\title{
A Critique of Control and Black Boxes:
}

\author{
Lit Mods of lan Hatcher's " $\forall$ (Total Runout)"
}

\author{
Álvaro Seiça, University of Bergen
}

Accepted Manuscript

Publisher version: Poetics Today (2020) 41 (4): 503-537. DOI: 10.1215/03335372-8720043

https://doi.org/10.1215/03335372-8720043

\begin{abstract}
This article analyzes Ian Hatcher's online and kinetic poem " $\square$ (Total Runout)" (2015) from a point of view of a critique of corporate and governmental black boxing, at the level of its code, text, visual output, sound, and live performance. The multimodal poem is part of the Drone Pilot suite, and it is presented in different versions: as a web-based work, sound piece, and performance. It remixes appropriated text from a WikiLeaked manual by the UK Ministry of Defence, essays on artificial intelligence, and Hatcher's own text. The overall versions of the work, understood as variable events, boldly problematize communication and cognitive processes in networks - whether they are implemented in computer systems by secret agencies or corporations. Hatcher's critique of black boxes entails recreating issues of security, control and surveillance, as digital systems are increasingly paving the way for less privacy and less knowledge about their inner workings. As a result, the poem questions the essence of privacy, redaction, and systemic violence, when access is a privileged asset of agents with security clearances or those with a deep knowledge of programming. This article presents " $\square$ (Total Runout)" in the scope of the poet's aesthetic program. Then, it analyzes its Web version's interface and source code. The kinetic poem's spatial and temporal dimensions are discussed via experiments that modify the source code. The methods here presented deform the poem's temporal display, by means of modifications, or what I call lit mods. Thus, the article proposes an approach for a more informed reading and understanding of digital kinetic poems, since they are ever-changing events. Finally, it locates the work's aural and performative versions in cultural and political context.
\end{abstract}

Keywords: Ian Hatcher, “ $\sqcup$ (Total Runout)”, digital poetry, sound poetry, performance, black box, control society, surveillance, WikiLeaks, lit mod

I am grateful to Ian Hatcher for the comments and material provided. A version of this article was presented at "Other Codes / Cóid Eile: Digital Literatures in Context," the first Galway Digital Cultures Initiative Conference organized by Anne Karhio in 2017. I thank the readers Scott Rettberg and C. T. Funkhouser. This project has received funding from the University of Bergen and, in its final stage, the Research Council of Norway and the European Union's Horizon 2020 research and innovation program under the Marie Skłodowska-Curie grant agreement no. 793147, ARTDEL. 


\section{Introduction: Unreadable Poetry?}

with no correlations in behavior there can be no common code

-Ian Hatcher, " $\sqcup$ (Total Runout)," citing Christopher G. Langton, "Computation at the Edge of Chaos"

Ian Hatcher's " $U$ (Total Runout)" (hereafter "TRO”) is unreadable. ${ }^{1}$ The work is impossible to be read closely because its text defies conventional modes of critical analysis. Its text is unreadable from a human point of view if we consider the cognitive processing of the fast-forward on-screen textual surface and its live sound output. The work permits only a time-lapse reading, in that glimpses of letters, syllables, and words emerge as perceptible entities, from time to time. The eye skims through the text while the text runs at a fast, unfathomable pace. From a machine point of view, however, the issue is meaningless, as the work is "readable"; that is, its code is executable.

Yet, I argue, the kinetic behavior of the text is part of the poem's functional and symbolic dimensions. My argument is that reading "TRO” against a background of critical discourse surrounding control societies helps foster a relevant contextualization of its cultural, aesthetic, and processual layers. In doing so, a field of possible meanings can perhaps emerge, if we further consider the poem as a manifestation of utterances that relate to a specific political moment.

\section{Hatcher's Aesthetic Program}

Ian Hatcher's body of work encompasses code, language, print, screen, Web, apps, sound, and performance. Code is used to reflect a thematic, conceptual, and tactical writing program. It becomes embodied writing and sound experience. This aspect is part of the author's transmedia and artistic approach. The same piece can be manipulated as a source for different versions. 
These derived events depend on their output and venue. For instance, the screen can become an extension, a complementary or contradictory visual element, or ambient.

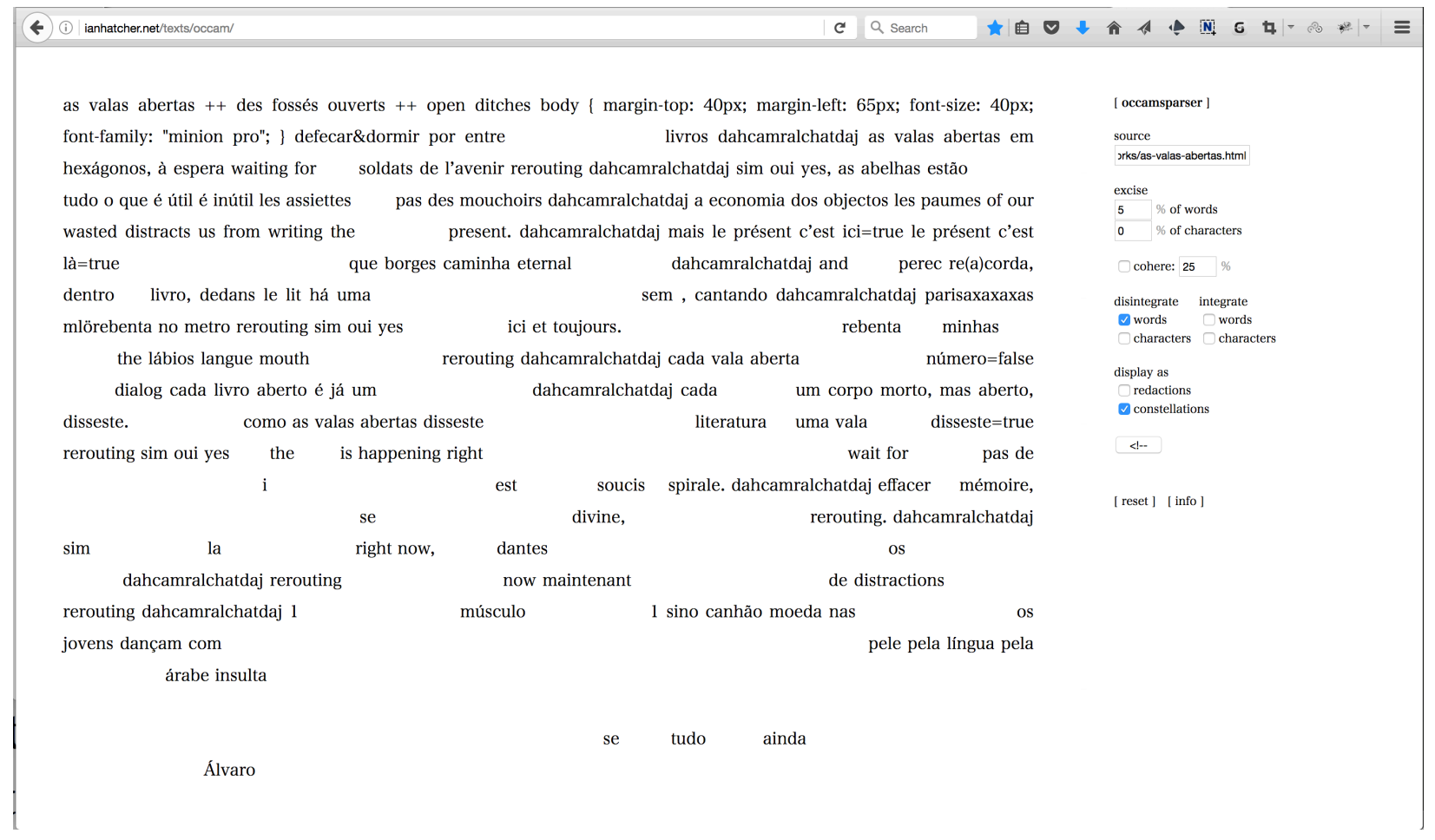

Figure 1. Ian Hatcher, "occamsparser" (2006). Screenshot, 2016. Courtesy of the artist.

As Hatcher (2015c: 13:18-13:58) elucidates:

I like reading alongside animations where there is not a direct connection between the text and what I am reading, and so it creates a separate stream where the text becomes more ambient or becomes a kind of flow that can't be followed, because I find reading something that is on a screen, really directly ... does an intentional thing for an audience — or does it to me, anyway — where I am following it but, on some level, it feels sometimes redundant, or it feels exhaustive ... whereas if I create separate streams then it gets that feeling of overflow or excess.

Ever since "occamsparser" (2006), Hatcher has been working with source texts as points of departure. "Occamsparser" is a "prose poem" but also a writing, visual, and displaying tool, a PHP (scripting language) parser that takes inspiration from the Occam's razor paradigm. Other writers can also use it as a composition tool, since it allows for the treatment, modeling, and 
parsing of any given website. The user can control, manipulate, and mask a source text by algorithmically changing parameters. These parameters are excision, disintegration, and integration of words and characters that can be output in "redaction" or "constellation" view (figure 1). When augmenting the percentage of excised characters, the constellation view echoes Eugen Gomringer's notion (1953), while at the same time it creates an "isolating deformance" (Samuels and McGann 1999: 51) of any given text, which is clearly performative.

"Occamsparser" reveals some of the strands of the author's writing program: incompletion, censorship, and erasure poetry, ${ }^{2}$ or "incompletion and excavation of language," in Hatcher's words (2015c: 01:28-01:35).

By writing and rewriting text that can be displayed in redactions, the poet recalls the censoring of documents and encourages a process of thinking with and through language. It highlights how language is treated at the level of institutions and governments, as well as the private and public spheres. Issues regarding access and black boxes are thereby already contained in this early piece, in that redacted documents prescribe a sociopolitical worldview. They evidence what is made available to be seen by the public and what is covert (Melley 2012). On the one hand, it seems as if Hatcher is making the case for transparency and open access documents, positions that mean opening sources with no restrictions - precisely the title of "Opening Sources" (2008). On the other hand, Hatcher wrote, "the prose poem text is intended to undercut that reading, as it's about inherent impossibility of open-sourceness in documents ('diaries'). In a similar way, 'Opening Sources' is undercut by its formatting constraints and the blackboxiness of its coding. It's making the open source argument somewhat facetiously."” Thus, the two-sided complexity of the open-source regime is embraced in the theme and concept versus its infrastructure. 
To wonder or not to wonder

Now; does Jon Snow know stuff? He knows nothing, rapidly displayed throughout the show

Dont you see that what i do is for views Jon Snow cried to himself .

As I said, I was just watching GoT Why you all up in my bitches

hail about the drugs? From the top of the table

you could see Bruce sit, ready for the meal during which he smoked a whole pack of long red clove cigarettes

Everyone remembered. Love did

Figure 2. Ian Hatcher, "Opening Sources" (2008). Screenshot, 2016. Courtesy of the artist.

"Opening Sources" (figure 2) is an online poem that is rewritten in real time by users that are readers and writers, in a collaborative pad-like system that allows for the continuous replacement of words. Moreover, when reading live, the poet vocally performs the text that the audience is editing in real time. Hatcher thinks of his pieces less as fixed forms - the strict, unchangeable, and final output at the written and visual levels — but more as open forms, that is, how processes and control mechanisms affect the vocal and sound levels of live performance. "Opening Sources," as Hatcher explains, opened a space for the performer to be controlled by the audience (Hatcher 2015c; Seiça 2015b). This, in turn, is then further taken into consideration as the author engages in subsequent pieces that deal with how control happens at the level of language, body, society, politics, media, and the Web.

"Ping" (2009) is a sound poem that deals with the connecting relations among human user, network, and host machine. Connectivity represents a social and psychological effect but 
also a human-machine relation. Moreover, the anxiety of connection we live in is translated in the piece as a claim about the network's recurrent ability to propagate both systemic violence and affect. The piece's textual and aural dimensions reinforce the exposure of that imperceptible feature "in discourses surrounding networks, [where] the tropes of connectivity, collectivity, and participation obscure the material practices of networks" (Thacker 2004: xviii). "Ping" can be listened to as an MP3 file, but when performed live it can include a screen projection of a pulsing white grid superimposed over a black background and a rotating tetrahedron. Within the Internet Protocol (IP) network, a ping provides a test connection to a host machine. ${ }^{4}$ It measures and informs if an IP address is accessible, that is, if it is connecting to a server and accepting incoming and outgoing packet messages, since the internet is based on packet-switching transmission processes. Developed in 1983 by Michael Muuss (n.d.) after "attending a DARPA meeting in Norway," Ping is a program for UNIX that effectively detects if an IP address can be reached as well as the round-trip time of data transmission. ${ }^{5}$ Hatcher's "Ping" draws from the pinging effect in sonars and networks, taken as a symbol of connection and data transfer via protocols. Furthermore, it meshes those analogies with references to the human "ping" of heartbeats and the connective bounds between human beings — networks of signals syncing human-machine relations. At the same time, it makes us aware of the historical relation between governance and governments, military compounds, technologic development, and the very beginnings of the internet, the ARPAnet, developed at ARPA in 1969, where the set of protocols TCP/IP (Transmission Control Protocol/Internet Protocol) were first implemented. ${ }^{6}$

Hatcher's "Ping" is read in a computerized manner that highlights its cybernetic character and the feedback loops of human-machine interaction, with intercalations of vocoder-like synthesized ping signals turned into speech sounds. The poem's semantic and aural dimensions 
emphasize the network as a space of fear and violence. Moreover, it stresses how de facto digital information is "greased" (Moor 1997, quoted in Ess 2009: 28); that is, a major property of digitally captured, stored, and transmitted data is its rapidly spreadable effect. This is not, however, an apologia of the benevolent capacities of information transmission but, rather, a bold critique of violence and the power of such apparently unharmful networks to replicate ubiquitous killings. In the United States, in the post-9/11 era, the reproduction of violence via networks has in fact increased. From direct invasion, such as the Iraq war, to indiscriminate civilian mass surveillance and preemptive attacks, ${ }^{7}$ US governmental agencies under the Bush and Obama administrations, including the National Security Agency (NSA) and the US Cyber Command, have put forward a whole new dimension of cyber warfare, of which drone attacks are a distinctive case. ${ }^{8}$ A set of instructions written in a physical part of the planet is run via a server in a device elsewhere, connecting streams of data for specific attack purposes and alienating the individual's responsibility over a strike. So coding is not just a mere abstract and logic way of reasoning about the world with programming languages. Algorithms are not acontextual and apolitical, that is, politically neutral. They are written and edited by humans, with specific needs, goals, and agendas. Therefore, they partake in a sociopolitical context. From this follows that programmers are secretively and nonsecretively hired by governmental military intelligence to put in practice information, corporate and political spying, and warfare operations to monitor and track persons, to script drone programs and exploits, and to install malware, that is, malicious code or virus. As Alexander R. Galloway (2004: 141-42) points out,

The exact opposite of freedom - that is, control — has been the outcome of the last forty years of developments in networked communications. The founding principle of the Net is control, not freedom. ... It is a type of control based on openness, inclusion, universalism, and flexibility. It is control borne from high degrees of technical organization (protocol), not this or that limitation on individual freedom or decision making (fascism). 
In devising "Ping," Hatcher questions the very essence and potential of coding as a type of labor with positive and negative sides, and the network as a space where such practice is activated. ${ }^{9}$ As Eugene Thacker (2004: xv) makes clear, "Understanding networks not as metaphors, but as materialized and materializing media, is an important step toward diversifying and complexifying our understanding of power relationships in control societies." Galloway and Thacker's (2007) theory of networks and Thacker's critical work on biopolitics can be related to the point expressed by Christopher G. Langton (1990: 31) on cellular automata and artificial life: "Correlations in behavior imply a kind of common code, or protocol, by which changes of state in one cell can be recognized and understood by the other as a meaningful signal. With no correlations in behavior, there can be no common code with which to communicate information." This fact raises further implications to an understanding of Hatcher's oeuvre-in particular, "Ping" and "TRO"- as a critique at the level of a common grammar in communication, "of common code, or protocol." Protocol allows for information exchange but also control. As I show below, Hatcher appropriates Langton's final line in "TRO."

At the sonic level, the performative strength of "Ping" relies on the turbulence and streamlined contrast enacted as a single-track utterance. The MP3 file contains a recording of a single voice —-with modulations - flexing a text with punctuations of "ping," a collage that could seem machine based when in reality it is human, not software, generated. The direction is, in fact, inverted. Instead of recreating his voice with software, Hatcher embodies network and software glitches using his own human voice. Thus, he transforms text by assembling and imitating the sonic features of software-generated voice. The piece ends, "Joining yet another 
steady stream, resolving into another steady stream, which will continue, which will continue, which, which, which, which will continue long after we are gone" (Hatcher 2009: 04:21-04:33).

C (1) www.springgunpress.com/ihatcher/workingmemory/

\section{shocks}

construction.

Figure 3. Ian Hatcher, "Working Memory” (2011). Screenshot. Courtesy of the artist.

In "Working Memory" (2011a), Hatcher starts a new process of engaging with very-fast animated text. The corpus of text displayed on-screen is precomposed, procedural, and generated, but scheduled. The same compositional remix technique appears in other pieces, such as "TRO" or "Plexus" (2014), where the verses are fixed as strings but the number of lines presented on-screen progressively augment and diminish as they bounce up and down. Yet Hatcher's "Working Memory" source text—available as a variable called "membox," which deals with the polymorphous nature of memory ${ }^{10}$ - gets reshuffled, a process that informs his subsequently performing practice of speed-reading and enacting voice stutters. Using two blocks that help create two points of eye fixation (figure 3), "Working Memory" addresses the capacity of the brain to retain and relate blocks of information at high speed, what cognitive scientists, 
psychologists, and vision researchers call working memory. The self-reflexive text explores the capacity to apprehend a high number of words per second, in a human attempt at syncing with a digital system. The piece's spatial composition can be seen to simulate message blocks or packets being transmitted in a network, in that information gets unified in the moment of the reading act; that is, coherence is given by its destination machine: Hatcher's host voice.

Employing mixed text composition techniques close to Flarf, The All-New (2015a) —a chapbook that is an offshoot from the Prosthesis (2016) series - presents appropriated text sourced from search engine results for "the all-new." Readers who search for this phrase online will find an overwhelming number of results that show nothing more than products to buy, mainly "all-new" car models. The All-New speaks to the "huge overflow of newness, novelty, in culture itself, that is so big that you can't follow it, and it just becomes insane," argues Hatcher (2015c: 19:12-19:21). The poet refers to 4chan.org as one of the sites where the overflow of information per second becomes impossible to cope with. Hatcher is not trying, though, to sell its readership and audience easy ways to read information faster but, rather, to critically emphasize the very nature of contemporary society: overproduction of goods, distributed, tracking, and tailored advertisement, hyperconsumerism, and waste. These conditions are felt and engaged with in a higher level by the netizen, who lives in times of a superabundance of data streams and screens. From a sociocultural point of view, these symptoms are identified and discussed, among others, by Gilles Lipovetsky (see Lipovetsky and Charles 2004; Lipovetsky and Serroy 2011), for whom the "hypermodern" age is redefining what individualism and privacy mean and conducting the homo ecranis and the homo connecticus toward cultural regression. These issues become relevant as we approach the multimodal work "TRO” from the standpoint of Hatcher's previous writing and layered artistic practices. 


\section{Read-Source: Reading the Source Code for "TRO"}

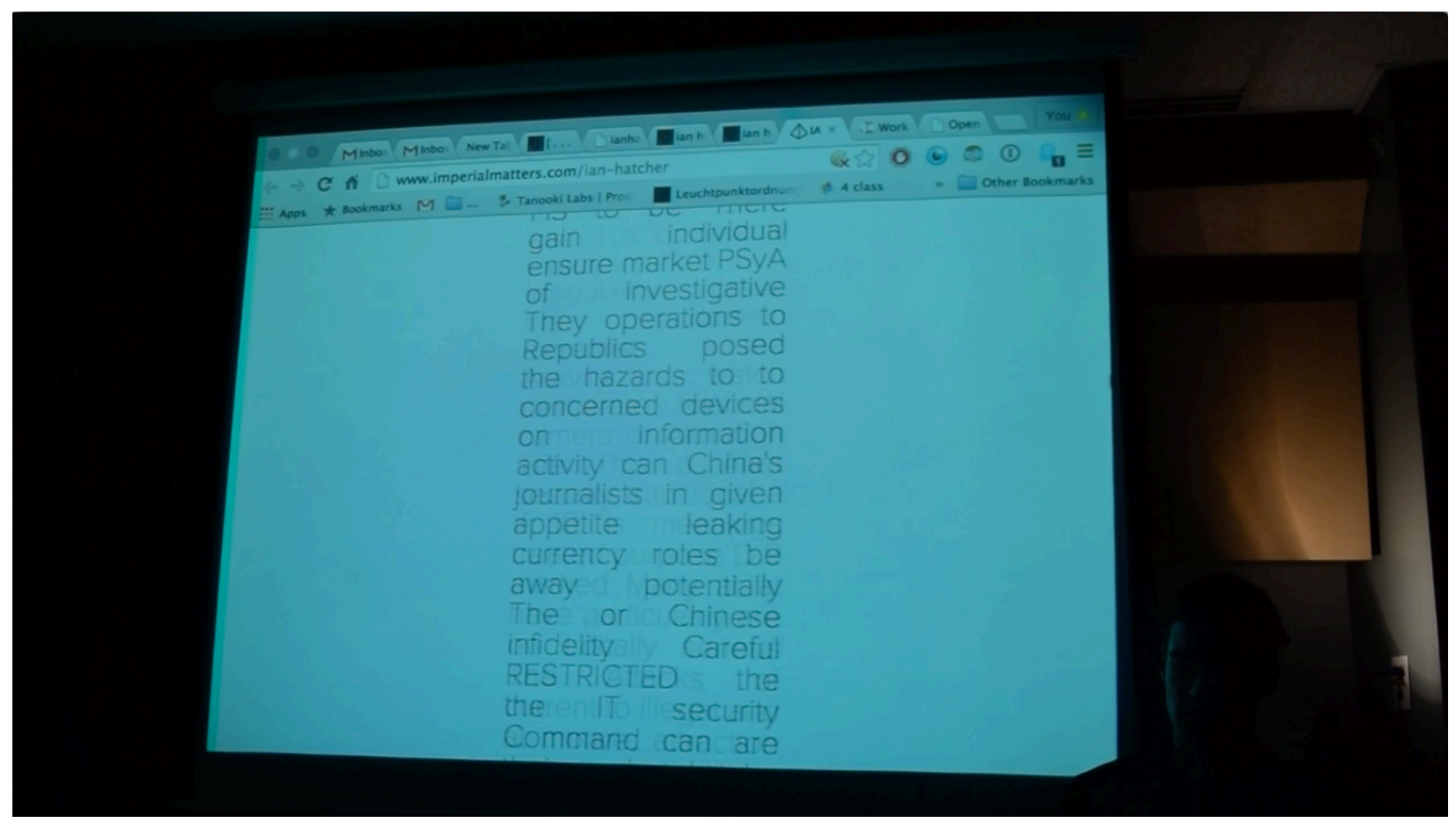

Figure 4. Ian Hatcher (2015c) giving an artist talk at the New Jersey Institute of Technology in Newark, on November 10, 2015. The screenshot shows " $U$ (Total Runout)." Courtesy of the artist.

The interface of "TRO" (figure 4) is quite simple, though the programmed functions are complex. Mies van der Rohe's functionalist dictum "less is more" could well be applied here. It is precisely in the scarcity of the work's elements that its powerful aesthetics resides. A mark of Hatcher's design, the elements and the overall composition are minimalistic and clear, and the rectangle is the preferred shape. Rectangles reflect the shape of boxes and blocks that Hatcher uses in many instances, but they are also the meaningful shape embodied in words - consider his earlier website URL address: clearblock.net. The source code for "TRO" first reads as follows:

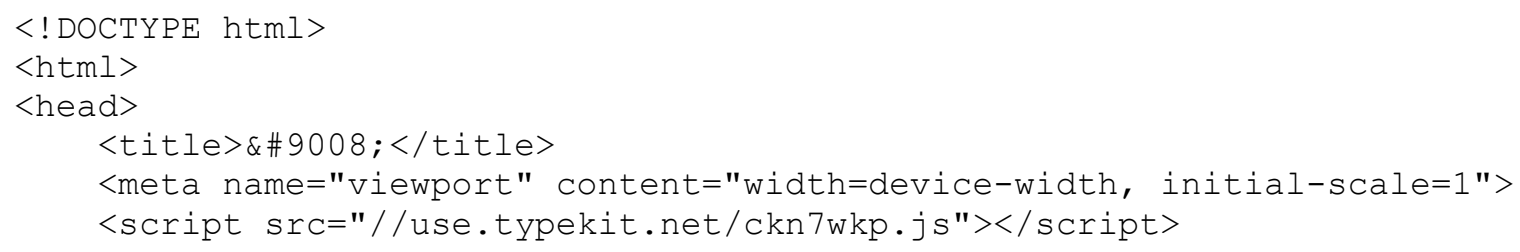




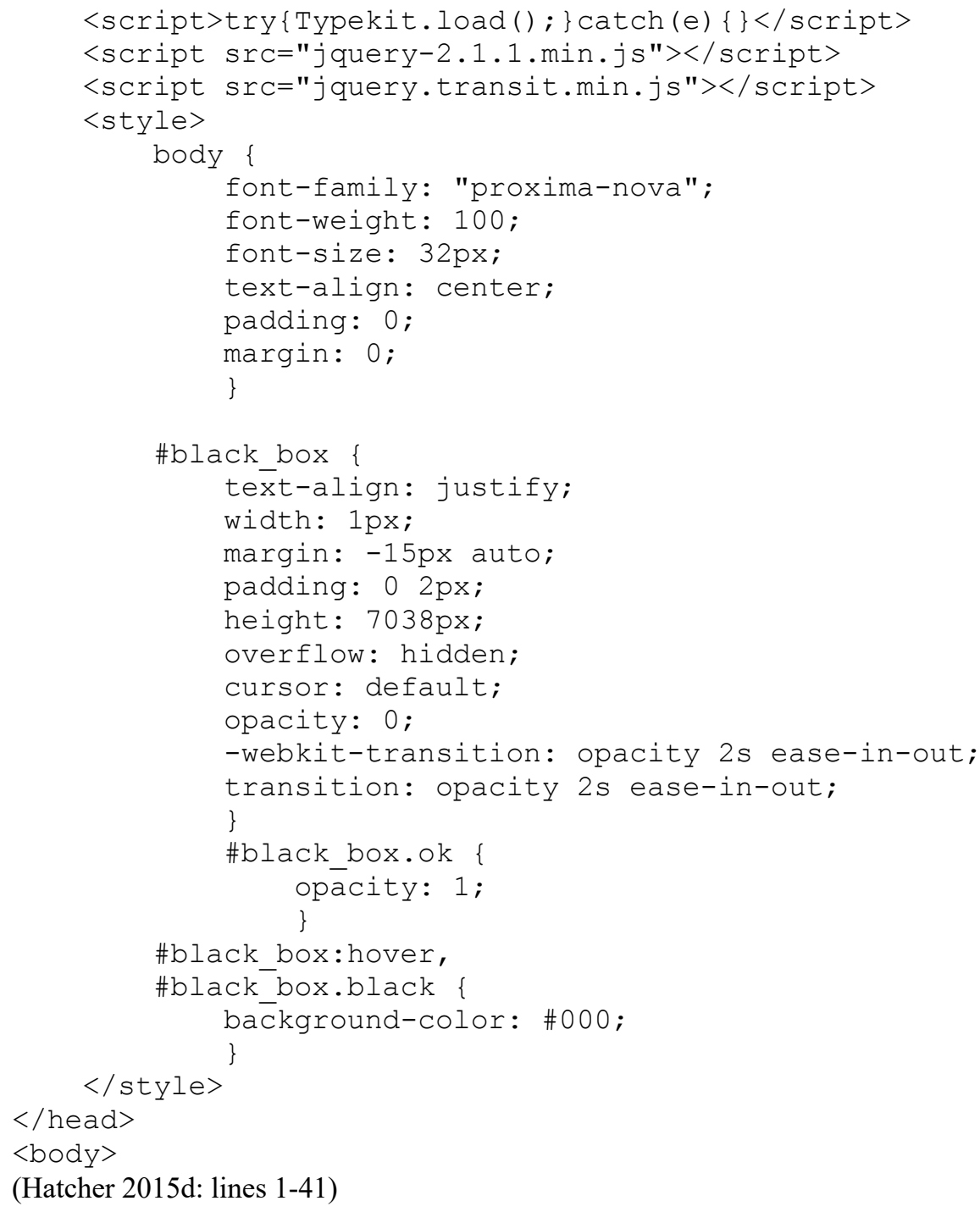

The spatial composition divides the screen canvas in three parts: a center-aligned stripe of justified text, which expands, like a curtain, back and forth, and assumes the shape of a long vertical rectangle, which can be scrolled down; and two white rectangles that border the text block from each side. Typographically, the open-source poem is styled using thirty-two-pixel Proxima Nova font, in black over white background. Viewing the source code allows us to understand that Hatcher has embedded the JavaScript library of the typeface via Typekit, formerly owned by an independent company but now owned by Adobe, and styled it with CSS (Cascading Style Sheets) language. Without the JavaScript library, the poem would be presented 
in the operating system default font. Mark Simonson's 2005 Proxima Nova is a thin font, which is sans serif, elongated, light, and elegant. ${ }^{11}$

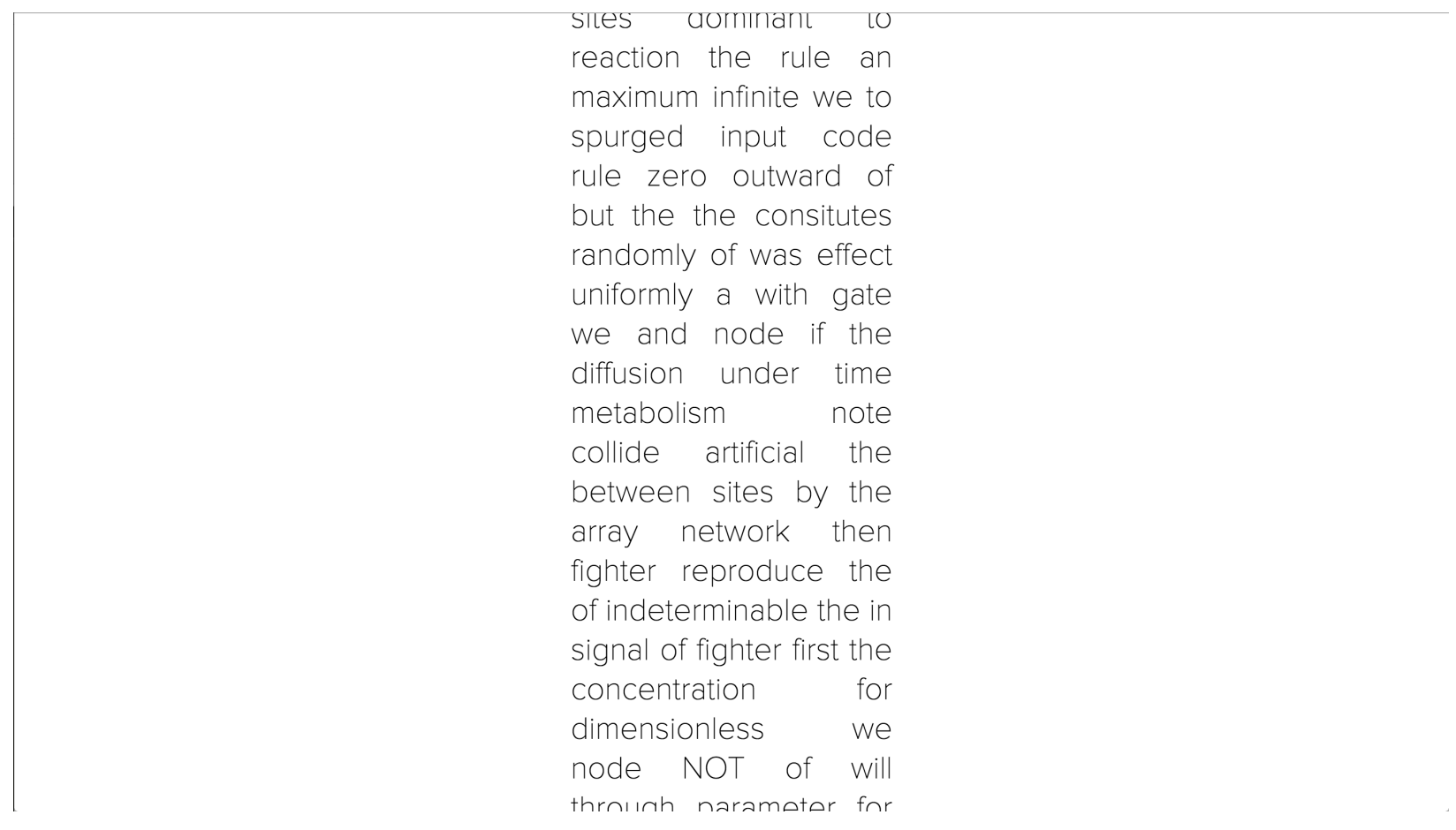

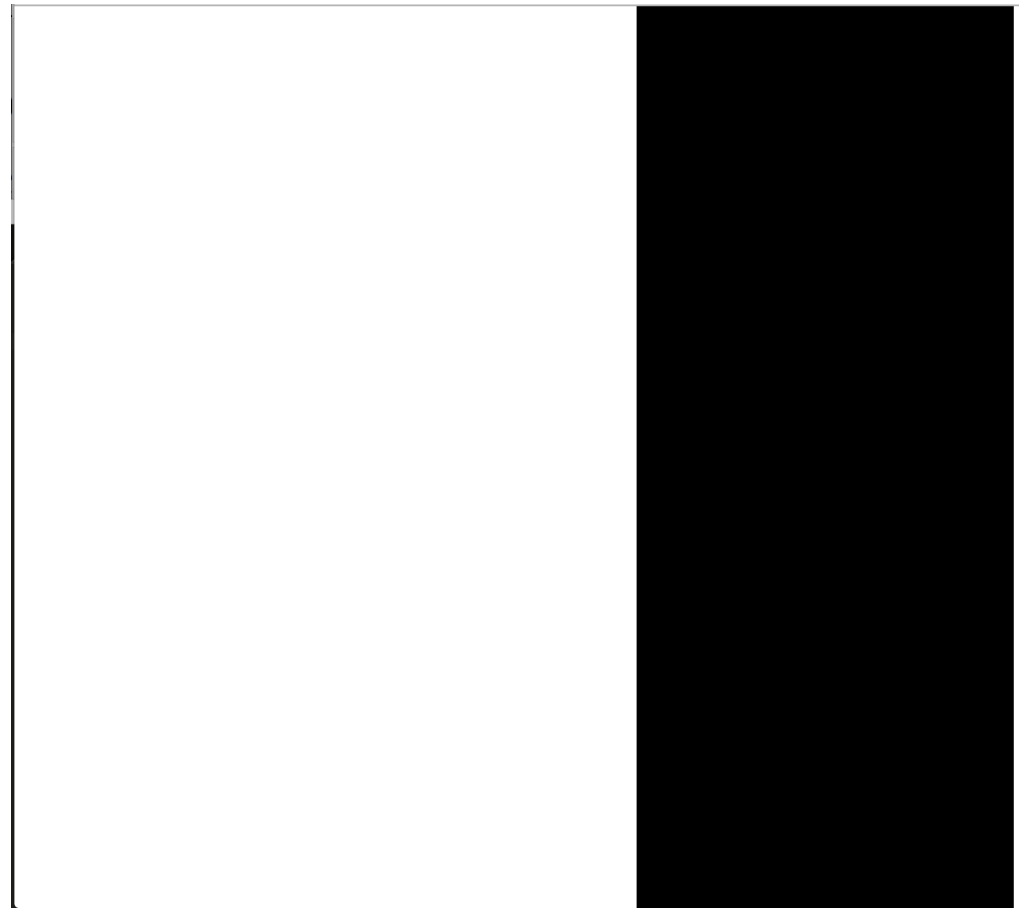

Figures 5-6. Ian Hatcher, “U (Total Runout)" (2015). Two states of the piece: without and with mouse over (hover). Screenshots. Courtesy of the artist. 
Let us now consider the interactive functions of the work. The reader-user's interaction with the piece takes two modes. First, as figures 5 and 6 illustrate, hovering over the text creates a transition to a black box_-see \#black_box above in the source code_-in which the screen turns into a white-like canvas with a middle black stripe. Second, clicking on the text opens a black curtain that propagates over the screen until it is 100 percent black. This action is irreversible. The reader-user cannot undo it, as there is no undo command, except for refreshing the browser and restarting the piece, that is, running the source code from line 1 again. This happens because once the browser window is all black the text can no longer be seen. Therefore, by trying to access more information, as the reader-user may request a sense of interpretation or merely read the material, the system replies with a contradictory granting permission: denial of access. In fact, when systems shut down, one can no longer access anything. This coded function reads as a reference to a symbolic and conceptual process that seems immediately to relate to some kind of hidden meaning in the text.

But what is that text that cannot be read? According to Hatcher, this text is better perceived as a flowing texture. It is indeed a texture as it moves at a speed impossible to be grasped by the receptors of brain cognition. David Jhave Johnston (2016: 19) interprets Hatcher's work as "perform[ing] a coded and sonic archaeology on language debris discovered within networks." Still, is this linguistic detritus composed of simple or even random streams of found material available online? Is it mere appropriation of meaningless material? Understood in that light, any text could go. But Hatcher's work is sharp. In fact, there are profound stylistic, formal, and thematic constraints. Here, appropriated texts, their remix composition, and their mash-up occurring on-screen may have an ultimate saying. They may be, as well, just part of the creative equation. The only way to access the text is to do some "underground" inspection, that 
is, reading the source code, which I call "read-source" in an analogy with the Web browser URI (Uniform Resource Identifier) protocol “view-source.”

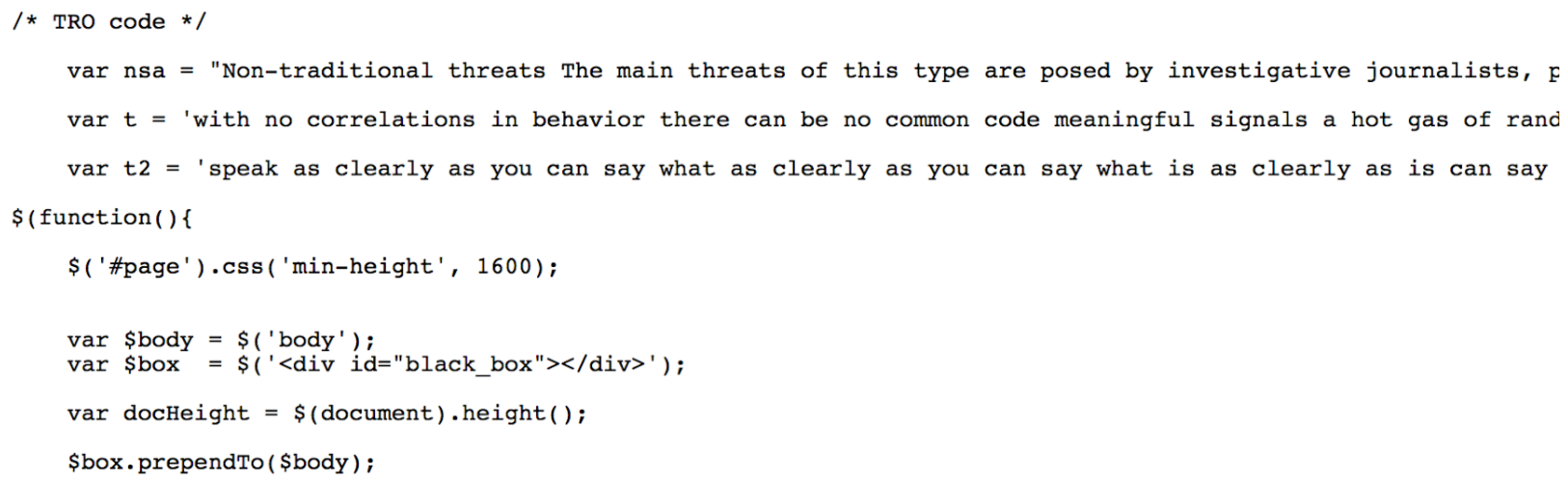

Figure 7. Ian Hatcher, " $\sqcup$ (Total Runout)" (2015): detail of the source code showing the three variables that contain the text that is generatively combined and displayed on-screen. Screenshot. Courtesy of the artist.

The source texts (seen in figure 7 because they are too long to be cited) are declared in three strings or variables (var) inside <script >: "var nsa," "var t," and "var t2." Var nsa is an appropriated text - a confidential document hosted in WikiLeaks. However, it is not an NSA document but a 2001 "Defense Manual of Security" by the UK Ministry of Defence, which sets the military regulations regarding counterintelligence and security. The report is cleared with level 1 in security standards, that is, "restricted." The report, leaked to WikiLeaks and posted in 2009, opens up with the following explanation about principles of security:

\section{The Definition of Protective Security}

0101. Protective security is the protection of assets from compromise. Compromise can be a breach of:

a. Confidentiality. The restriction of information and other valuable assets to authorized individuals (e.g. protection from espionage, eavesdropping, leaks and computer hacking).

b. Integrity. The maintenance of information systems of all kinds and physical assets in their complete and usable form (e.g. protection from unauthorized alteration to a computer programme). 
c. Availability. The permitting of continuous or timely access to information systems or physical assets by authorized users (e.g. protection from sabotage, malicious damage, theft, fire and flood).

(UK Ministry of Defence 2001: 1-1)

The WikiLeaks summary points out that "the document includes instructions on dealing with leaks, investigative journalists, Parliamentarians, foreign agents, terrorists \& criminals, sexual entrapments in Russia and China, diplomatic pouches, allies, classified documents \& codewords, compromising radio and audio emissions, computer hackers - and many other related issues" (WikiLeaks 2009: n.p.). The manual defines five "threats to security" to governmental assets: espionage, sabotage, subversion, terrorism, and "non-traditional threats posed by other individuals or organizations." It is the "non-traditional threats" that Hatcher uses as source text, bundling parts of the manual as they were excerpted by WikiLeaks:

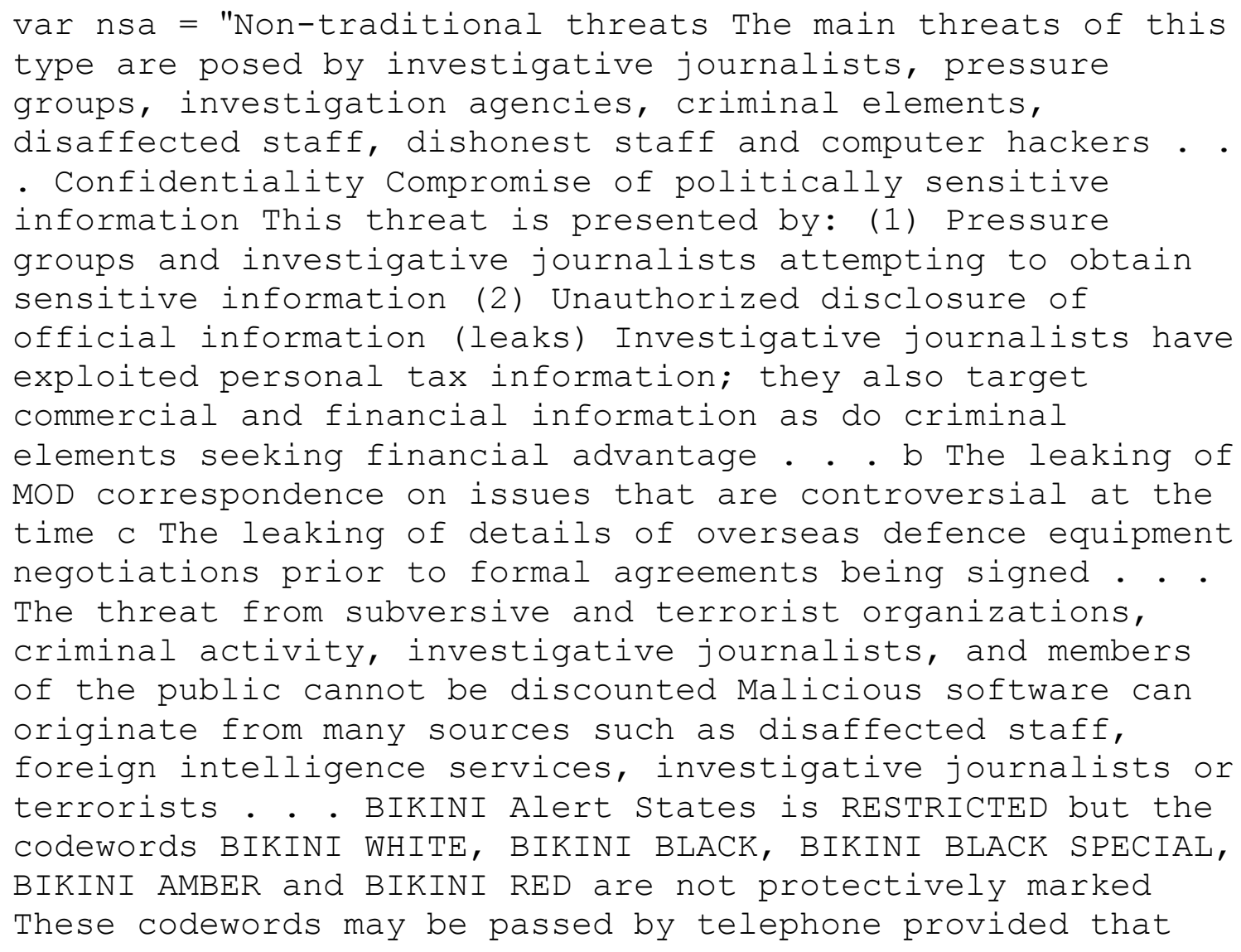


they are not qualified in any way . . . Chinese intelligence activity is widespread and has a voracious appetite for all kinds of information; political, military, commercial, scientific and technical. . There is an obvious economic risk to the UK . . In certain key military areas China is at least a generation behind the West The chinese may be able to acquire illegally the technology that will enable them to catch up The real danger is that they will then produce advanced weapons systems which they will sell to unstable regimes . . . Chinese intelligence activity is very different to the portrayal of 'Moscow Rules' in the novels of John Le Carre The Chinese make no distinction between 'information' and 'intelligence' Their appetite for information, particularly in the scientific and technical field, is vast and indiscriminate . . TRAVEL BRIEF FOR VISITS TO RUSSIA AND THE FORMER SOVIET REPUBLICS . . In view of the poor state of the Russian economy, the Russian Federation Intelligence Services (RFIS) place a high priority on information to bolster their economy, scientific and technical information, and on information to help advance their pol itical influence This extends to the theft of patents and to seeking detailed information on Western scientific developments They also have an interest in political reporting, alongside their more traditional targets such as Western Defence and Security, eg NATO The SVR (foreign intelligence service) and the GRU (military intelligence) try to recruit British subjects to work for them in the United Kingdom and elsewhere . . We know it sounds like a spy movie, but as well as having wide networks of agents and informers, the FSB (Russian security service) makes extensive use of sophisticated technical devices In the main hotels all telephones $\mathrm{c}$ an be tapped and in some rooms visual or photographic surveillance can be carried out, if necessary using infrared cameras to take photographs in the dark. . Irregularity in personal behaviour may also lead to trouble The FSB may attempt to capitalise on sexual liaisons between visitors and lo cal nationals . . the FSB may attempt to compromise and subsequently blackmail through knowledge of marital infidelity or sexual activity - . RFIS officers may make approaches using the cover of another nationality, for example Eastern European or Scandinavian, to disguise their true allegiance.

(UK Ministry of Defence 2001, quoted in Hatcher 2015d: line 45) 
As it may now be clear, this text accounts for a precise secretive worldview and geopolitical tactics exerted by the British government. Moreover, such is the Orwellian dystopian view that it openly describes the danger of journalism and research, the so-called investigative journalism, as a threat to governance and the "compromise of politically sensitive information," as if journalism and governance accountability should be two uncorrelated notions. Besides the implications at the national and geopolitical level, this document shows a deep sense of arrogance and Western superiority, which is a common denominator in descriptions found in the US cables and the UK documents leaked to WikiLeaks in 2010-11. While having plain rules and being surprisingly absurd at times (e.g., "Chinese intelligence activity is very different to the portrayal of 'Moscow Rules' in the novels of John Le Carre" [sic]), it is very different from the source texts contained in the variables " $\mathrm{t}$ " and "t 2 ," which have been composed or written by Hatcher. Var t, in part, reads as follows:

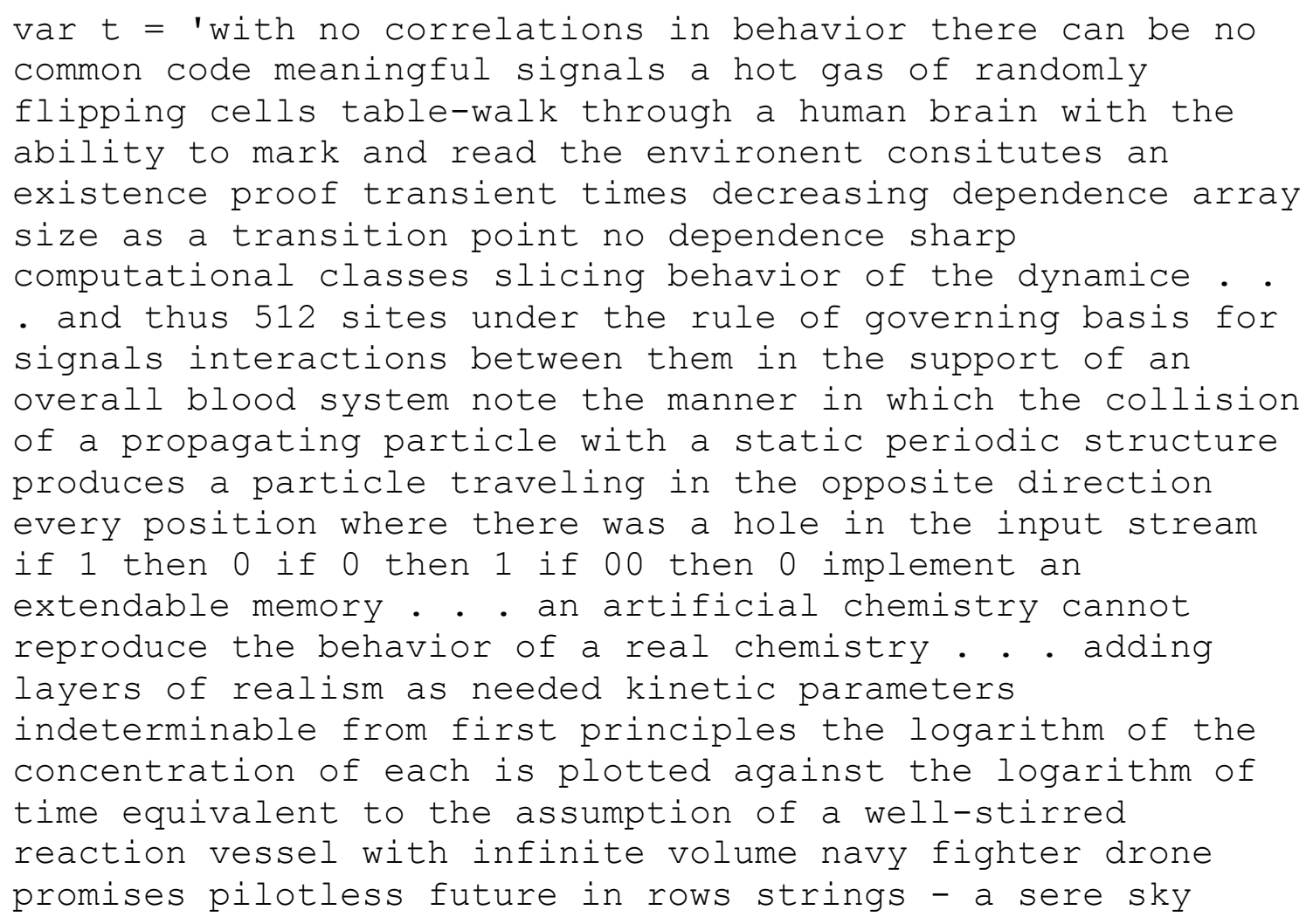


spurged humming expanding \&times; \&times; \&times; with no correlations in behavior there can be no common code. (Hatcher 2015d: line 47)

This array of text is made out of chunks of text that constitute a whole, and then it has been copy-pasted six times. The text comprises cut-ups from different sources about complex systems, artificial intelligence, biologic systems, chemistry, and unmanned systems and aerial devices, such as drones, that have been appropriated, copied-pasted, and reshuffled. For example, the first two segments "with no correlations in behavior there can be no common code / meaningful signals" are taken from Langton's "Computation at the Edge of Chaos: Phase Transitions and Emergent Computation" (1990: 31). Another segment, "a hot gas of randomly flipping cells," is also extracted from Langton's article (1990: 29), while “an artificial chemistry cannot reproduce the behavior of a real chemistry" appears in Richard J. Bagley and J. Doyne Farmer's “Spontaneous Emergence of a Metabolism” (1991: 107), concerning autocatalytic networks_all these authors were employed at the Los Alamos National Laboratory, and were part of the theoretical division of the Complex Systems Group. Furthermore, the block of text "navy fighter drone promises pilotless future" is extracted from Eric Niiler's Web article "New Navy Fighter Drone Promises Pilotless Future" (2012). It seems as if Hatcher is extracting these texts to establish parallels in seemingly complex autonomous and adaptive networked systems, which are artificially run, self-regulated, self-governed, and black-box organisms: secret governmental agencies, computer systems, drones, biological systems, L-systems, cellular and code automata, and genetic algorithms. This claim is emphasized by var $\mathrm{t} 2$ :

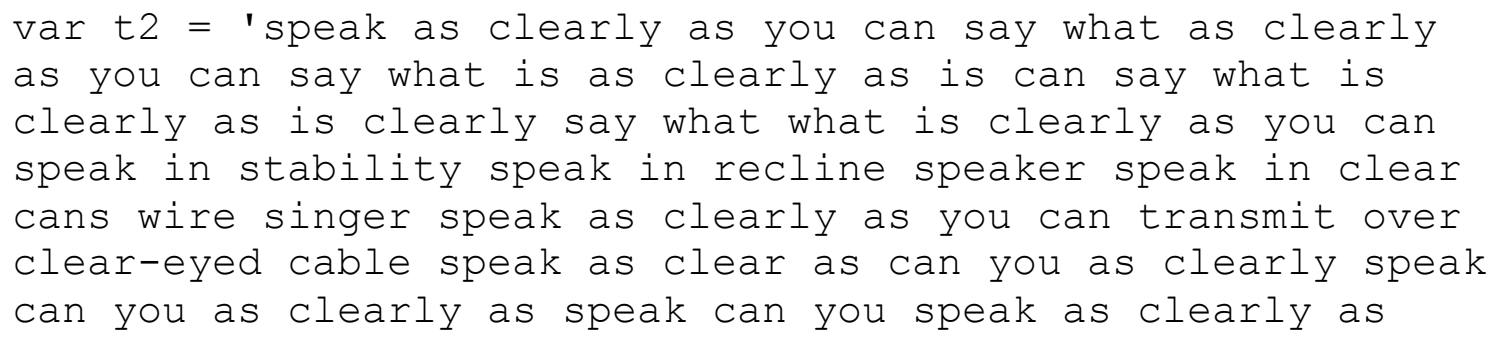


speak clearly as can you speak clearly you speak speak in a snowstorm speak in an ice castle speak in a dead computer speak in a diamond mine speak in a silver lining speak in an empty node speak in a speaker i can hear what you are saying $i$ hear what you are communicating saying as clearly as you can i hear it as clearly as i can clearly i hear clearly you can speak as clearly as you can speak as clearly as you can it is the right you have left don\'t remember last forever don\'t remember last forever don\'t remember last forever don\'t remember last forever don \'t remember last forever don 't remember last forever in a church of color bars which have lost color which have become figure on ground stained glass opens a seascape a final dream a balcony trust forms which come in pairs key values radio storm flood of cats delineated and taxonomized box them up and seal them in chambers of the visible or the divisible or the devisable or the devious or the matter of fact or the allusive or the allegorical or the spectacular or the tedious or the aesthetically suspect or the ridiculous or the caustic or the momentarily beautiful or the toothsome or the narrative or the comfortingly familiar or the comfortingly unfamiliar or the disturbing or the incomprehensible or the offensive or the irritating or the deliberately difficult.

(Hatcher 2015d: line 49)

Now, Hatcher wrote the text embedded in this array. But the cited excerpt was then recomposed by means of copy-paste.

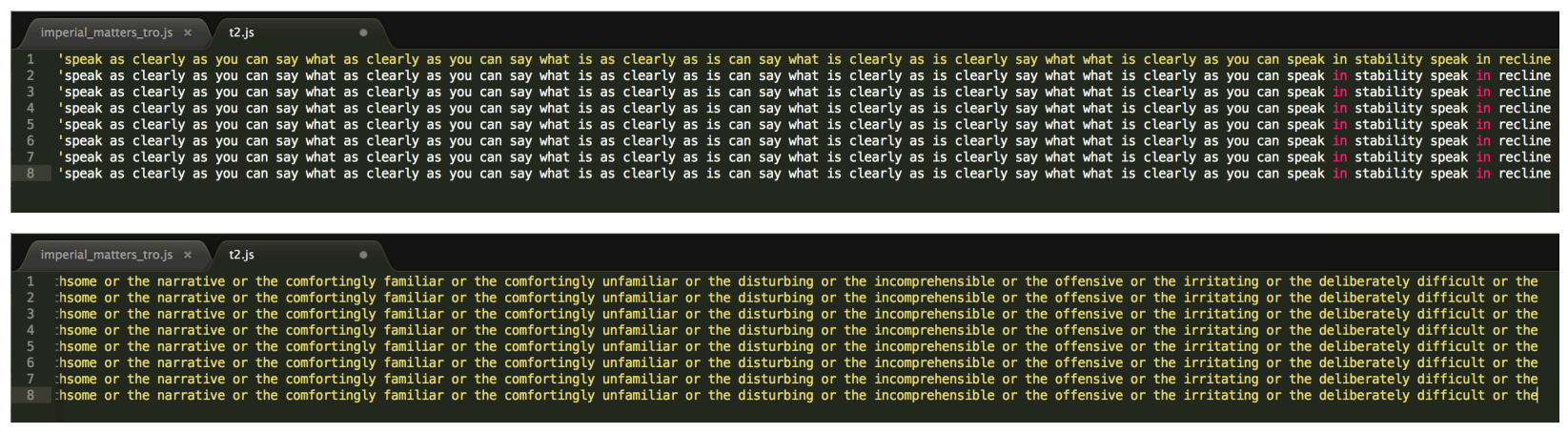

Figures 8-9 Text editor analysis of the variable $\mathrm{t} 2$ ("var t2") shows the same excerpt copy-pasted eight times.

As we can read in figures 8 and 9, the whole text block is repeated eight times. In addressing a second subject, or an "othered" self, the request "speak as clearly as you can"—which is a 
common sentence that can be found in speech test and in educational and employment manuals_-refers back to modes of communication in speaking and hearing: "Delineated and taxonomized box them up and seal them in chambers of the visible or the divisible or the devisable or the devious or the matter of fact or the allusive or the allegorical or the spectacular or the tedious or the aesthetically suspect." It thus represents an incitement to open modes of communication and to bypass the black box.

\section{Lit Mods}

As the source code reveals, these three variables, var nsa, var $\mathrm{t}$, and var $\mathrm{t} 2$, are generatively entangled and reshuffled on-screen. Using the scripting language JavaScript and the open source interaction and animation libraries jQuery and jQuery Transit, ${ }^{12}$ Hatcher codes the temporal and kinetic aspects of the work. In fact, without these two libraries, the work would be a blank canvas. If we view the neatly laid-out source code, we find valuable information in the programmed algorithms and data structure (lines 59-81):

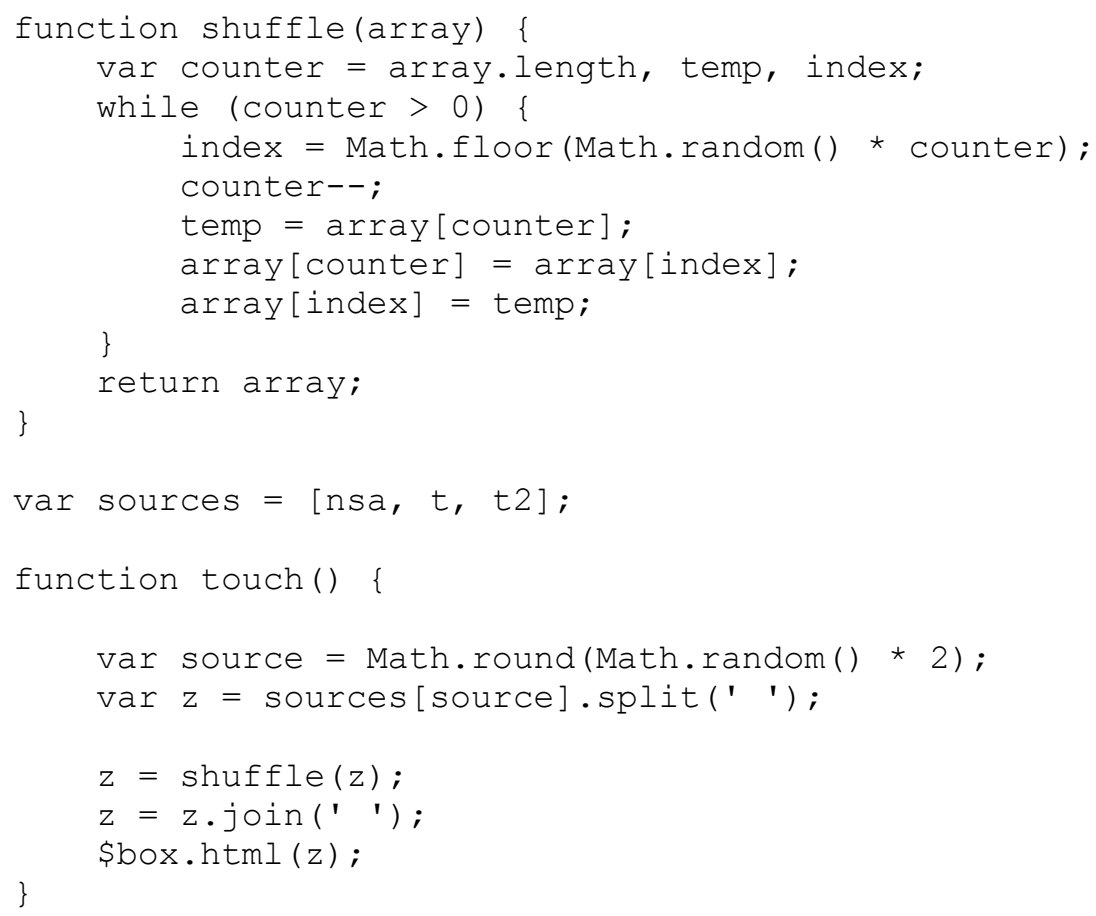




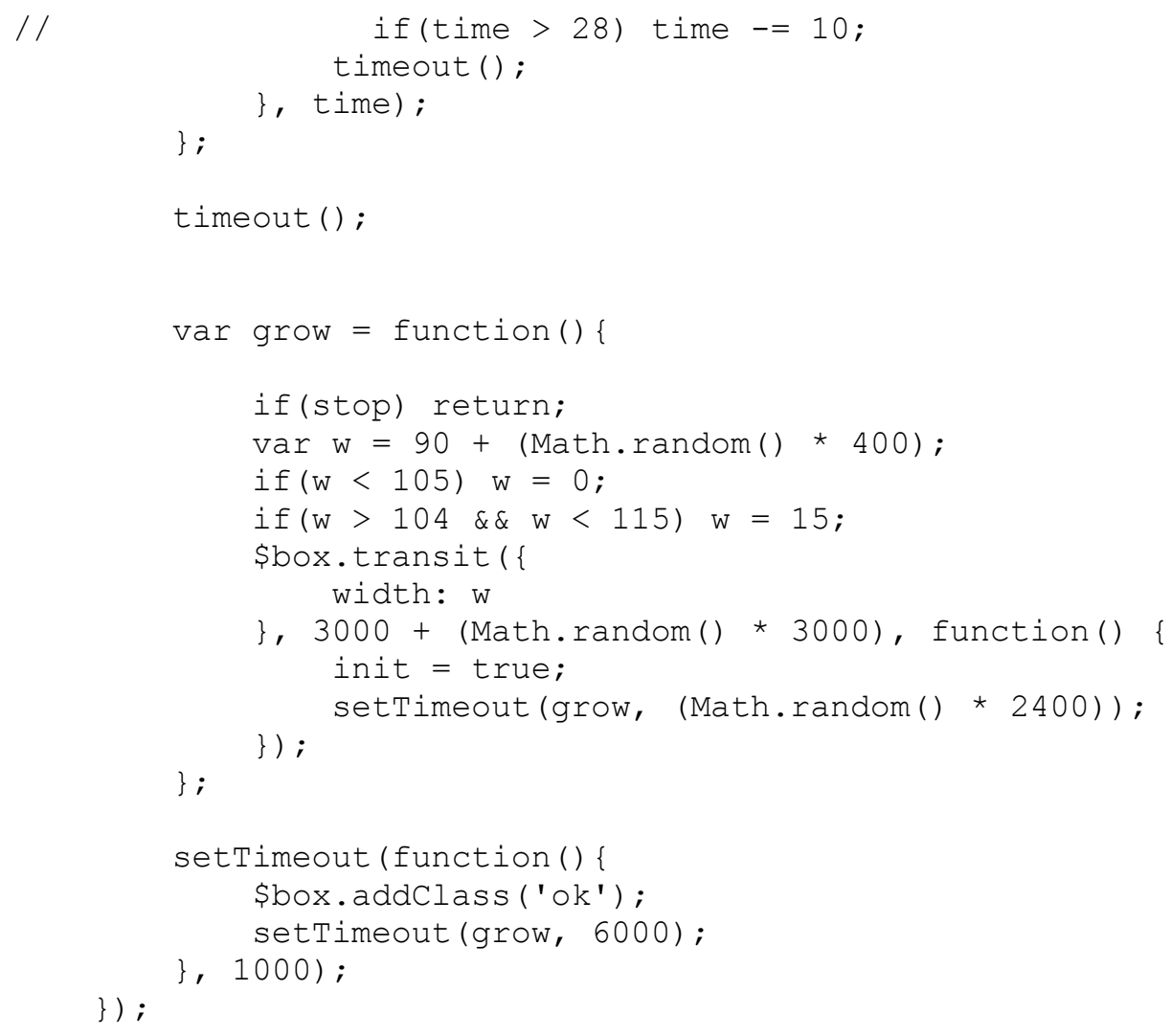

Now, we have on-screen animations due to the jQuery Transit library and the setTimeout () calls, and the duration argument given by the timers. The variable time sets the thirty milliseconds parameter ( 0.03 seconds), which is the duration of the textual shuffle replacement, and the 6,000 milliseconds parameter as the duration of the block of text (box) to grow:

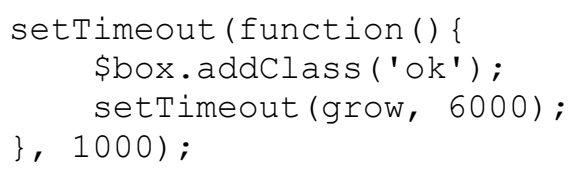

As we think about the way the text gets reassigned as an event, it clearly cycles too fast to be perceived. Slowing down the speed will surely reveal the entangling behavior of larger portions of language. One way to account for and perceive these changes is by modifying the source code time inscriptions and exploring, through trial and error, the programmed conditions and the effects of temporal functions as they are executed and displayed on-screen. Manipulation of the 
time parameters described above, in a modified version of "TRO," can follow (boldface signals interval changes made by the author):

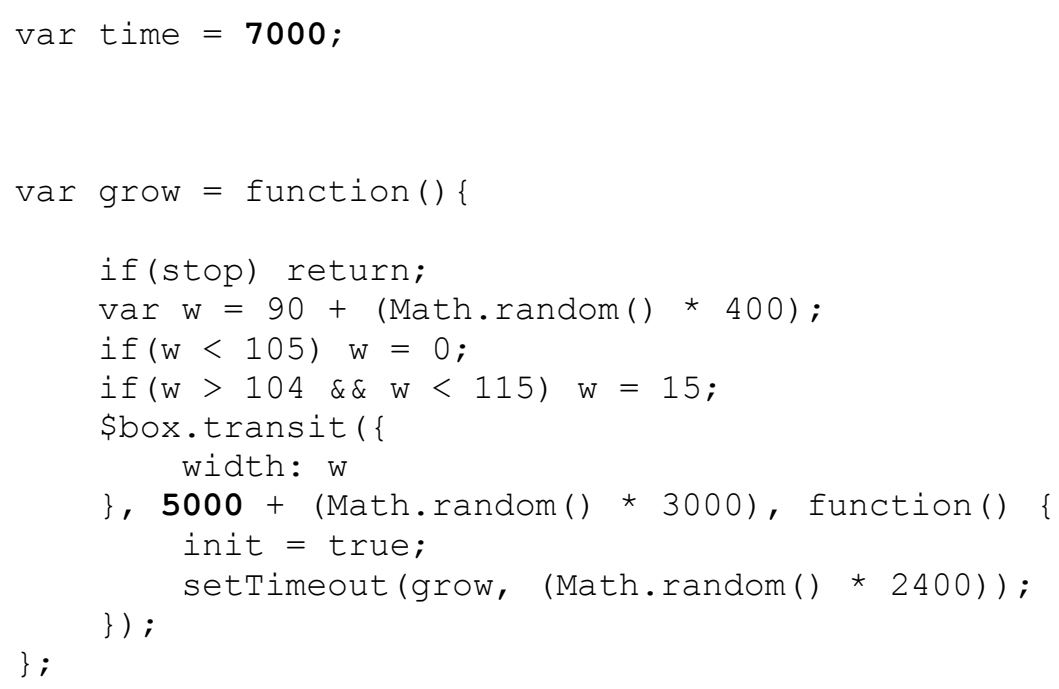

(Hatcher 2015d: lines 3; 138-50, emphasis in changes mine)

This experiment drastically transforms the textual running speed, but more important, it leads to an important discovery. ${ }^{13}$ In the original work the text changes and reshuffles, according to my calculation, thirty-three times per second, that is, one second divided per 0.03 seconds. By increasing that value to 7,000 milliseconds (seven seconds) — since the text is justified — we start perceiving that its lines break in different ways concurrently to the curtain-like motion of the block up until fifteen units' width. In addition, to smooth the curtain expansion, I changed the parameter 3,000 milliseconds to 5,000. Therefore, it is possible to see the increase of transitions in the text behavior, given that its words are modifying placement as well- the position of words per line. Thus, placement and replacement multiply the dislocations of words in space.

Another way to explore the temporal and spatial dimensions of the poem is by using a screen recorder tool. For that matter, it might be useful to create slow-motion screencasts of the work, slowing down the speed of the piece running on a browser. A time-lapse movie can be achieved by recording an event at very low frame rate and then speeding it up when exporting it. 
However, "TRO" is an event not of slow but of fast mutations, so we need to slow it down. Capturing at an average rate of 0.3 frames per second (fps), the first export of the file was done at $200 \mathrm{fps}$, which highlights the transition behavior, and then at $20 \mathrm{fps}$, which would show about one transition per second. This process creates a time-lapse video in slow motion. These parameters were based on Hatcher's information that the poem cycled twenty times a second. Studying the source code and understanding that it actually cycles at an average of thirty-three times per second suggested that a different method was needed. The second experiment set the screencast sequence timebase to $30 \mathrm{fps}$ and then reduced the speed duration of the whole clip to 10 percent. Therefore, the initial one-minute recording was slowed down, becoming ten times longer, that is, ten minutes long. As productive as it might be, this surface method did not in fact reveal as much information on the text behavior as the source-code-modified version did. ${ }^{14}$

While it might be problematic to move away from the intended sequential speed, these "lit mods," or modifications of literary works, are essentially altered versions of original works (Seiça 2020) that help in questioning and discovering their vital aspects, when it comes to their inner mechanisms, content, form, and process. These lit mods can be understood within the experimental artistic and critical practices of game modding, open source, and remix culture. Yet literary studies also has its own tradition of experimental criticism. In relation to my approach, the "deformative criticism" proposed by Lisa Samuels and Jerome McGann (1999: 36-37) applies similar methods to study poetry. Modding a digital poem by, for instance, changing intervals in timers, shares affiliations with Samuels and McGann's "altering deformation," in that the modifying deformation of the temporality of reading might help us grasp text entanglements and transitions and to regard the poem anew. The transcription below accounts for three of those 
transitions, though without the text's graphic justified layout. A row of letters mutates itself from:
a
a
$\mathrm{t}$
$\mathrm{k}$
$\mathrm{n}$
i
$\mathrm{u}$
$\mathrm{t}$
$\mathrm{t}$
$\mathrm{X}$
t
f
b
i
W
W

b

$t$

a

0

i

into
can you clearly an spectacular speak is dead singer clearly remember speak the or don't last in can as narrative pairs you and divisible is familiar up the as can or castle can remember clearly speak speak the speak chambers suspect or values computer speak what them can speak cats $i$ in 
dead as storm $\mathrm{i}$

balcony or you

forms an

and then
employees the examples talk would to often visit the probable of developments rigorous Technical intelligence the intelligence no A software are external Def obliged Def the Characteristics date, preparing Services also details, realized given disastrous marked from The subsequently cost such financial considered any United disaffected as locally the voracious of of may travellers little influenced territory up as where (especially either taken to the European codewords unwittingly, cannot special Or, roles by subversive and from used as in telephones premeditated might sensitive him the to take exploited this extremist Chinese to terrorists the political, obtain if be reporting Foreign from (Hatcher 2015d)

In fact, the reader might see these transitions only once in a reading period. The transcription of these excerpts proves that the text entanglements per se, when they are frozen as such, are not the most important, and that modifying the temporality of its display, as a live event, can produce a better understanding of the output. Besides, it is in Hatcher's performance that they become activated as meaningful literary and aesthetic entities.

Yet, changing the temporality of the presentational mode also changes the affective experience, the aesthetic qualities of reception at the level of emotion, and perception from the point of view of the reader and viewer. Art "lasts no longer than its support and materials," claim 
Gilles Deleuze and Félix Guattari (1994: 163). In their point of view, the artistic experience—as an autonomous quality of the work of art-is "preserved [as] a bloc of sensations, that is to say, a compound of percepts and affects" (164). Jorge Luis Borges (2014: 143, my translation)—for whom space can be measured by time, and nightmare was the oldest of literary genres - when writing on Attilio Momigliano's literary criticism considered that "aesthetic comment is the normal method. We judge books for the emotion that they evoke, for their beauty, not for reasons of doctrine or politics." This is Borges, of course, raising sensu over intellectu. Sensu and intellectu, though, go hand by hand.

Considering the perceptual and affective side of the tempo Hatcher sets is decisive. Slowing down its tempo or, for that matter, grabbing a screenshot can help us read some of the mash-ups of text happening on-screen, but more important, slowing down the tempo allows for a perception of kinetic behavior, a complementary reading that further informs the difference between interpreting a static object, such as a book, print poem or source code, and an event. As Hatcher (2015c: 22:32-22:49) elucidates, the behavior of "TRO" is "generating and chaining itself continuously over time, but it is doing it with preset vocabulary that I chose deliberately, and gave to it. And it's flipping between three different texts about twenty times a second when it's running on a system that can do that." Therefore, machine processing time, CPU time, code execution time while the browser reads it, and the network time influence the final display tempo of the work. As Stephanie Strickland points out, these "concurrent times" (Seiça 2015a) actually define and constrain the perception of any web-based event. If the poem is running on a system that can perform the reshuffling without major delays, "you get these bits of language that allude to military industrial complexes" (Hatcher 2015c: 23:46-23:58). 


\section{The Black Box: Surveillance, Redaction, and Systemic Violence}

What is compelling in Hatcher's oeuvre is not the exploration of the documentary form and subsequent appropriation of secret documents but, rather, how these sources are activated, how, for instance, the interaction of the user enacts the redacted technique of the blackout. ${ }^{15}$ These strategies are dynamically, visually, and conceptually put in practice, transcoded onto the screen, but also evoked and recreated as embodied voice performance. Cycling through media and languages, "TRO" is striking as a point of departure that forks different iterations of events aiming at creating awareness of black boxes. These events are prompted by expressive translations of code and encoding. First there is the coding in JavaScript, then there is the onscreen visual and language output, which the author describes as a "screen poem," and lastly, there is the performance of the piece, whose output is another series of language-broken code. Even the title of the work is a code: U+2330. This Unicode character's equivalent decimal HTML encoding entity is \&\#9008; and it is translated by the browser as 4 , a symbol that means "total runout," a technical variable measuring the tolerance control over the geometric variation of a surface. Thus, it can be understood as relating to the control exerted over a surface of text, or the denial of access, as the piece ceases completely to be accessible, almost as a denial-of-service attack scenario. This issue is prominent in that "TRO" is part of a larger suite titled Drone Pilot (2015b).

In the source code of Hatcher's website, we used to find informative paratext as lingering HTML comments about Drone Pilot:

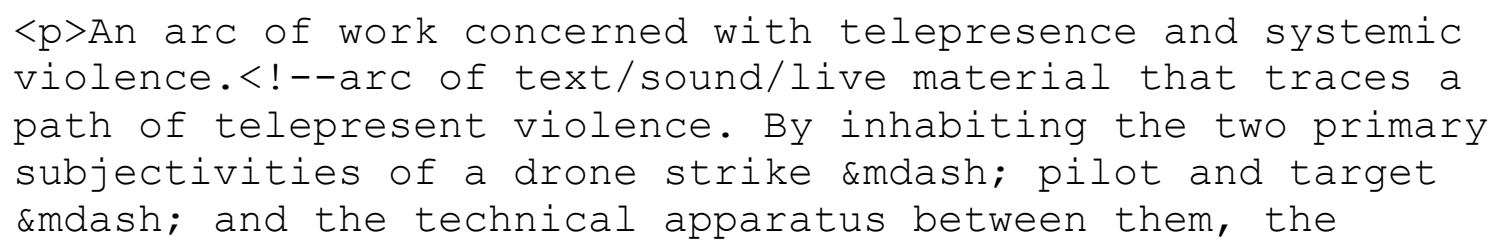




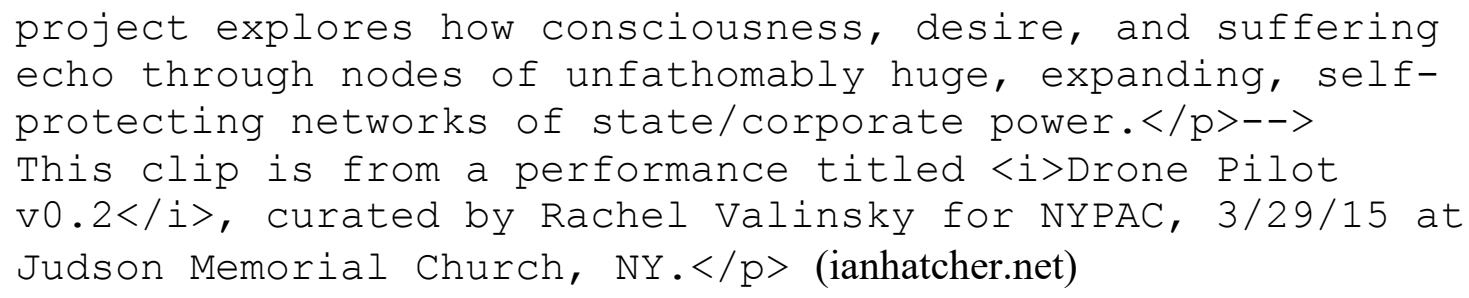

Contrary to "Plexus," which is a lyric poem, "TRO" stems from the fact that violence needs to be treated — presented and represented—in a strategic way. As Ben Lerner (2016: 62) asserted, when preparing to analyze Claudia Rankine's Citizen (2014), “The lyric — that is, the intensely subjective, personal poem — that can authentically encompass everyone is an impossibility in a world characterized by difference and violence." As such, "TRO" and the Drone Pilot suite partially "speak" the language of its governmental emitters, and in uttering it they counter it. As Hatcher clarifies, Drone Pilot (2017) contains five "sections" or "songs" that are performed in versioned ways: (0) “The Base,” (1) “Connecting,” (2) "Speak as Clearly as You Can” (“TRO”), (3) "Private," and (4) "The Hive."16 These "schematic" parts address the binomial private/public, in relation to the themes of systemic violence, drones, and black boxes.

The black box represents a system that cannot be fully accessed, or whose inner mechanisms cannot be fully graspable. In computer science and engineering, a black box is a designed system or object that can be employed with an understanding of input and output, but not of middle processing, that is, without an understanding of how it works. According to the Oxford English Dictionary, black box refers to a "flight recorder in an aircraft," where typically sonic and flight data is recorded. Its notion extends to "a complex system or device whose internal workings are hidden or not readily understood." ${ }^{17}$ As a "technical apparatus," the black box in a drone device directly streams flight data back to its remote-control station or stores 
flight logs via software. The remote-control station, commanded by a pilot, operates the device via a network.

As Paul Virilio (1999: 17) warned in a 1996 interview, “ubiquity, instantaneity, immediacy," combined with ever-smaller drone devices, diminish democracy. In fact, Virilio quotes Ernst Jünger's Glass Bees in relation to nanotech wasp drones, which is the main topic addressed in Hatcher's “Hive.” Commenting on Virilio’s work about speed and politics, Wendy Hui K. Chun (2006: 209) remarks: "Virilio argues that because telecommunications networks work at the speed of light, speed becomes as important as, if not more than, time and space." The circulation and escalation of violence via networks become even more obfuscated by complex distributed systems. "Protocol's native landscape is the distributed network," argues Galloway (2004: 11), and as such, agency and accountability also become distributed, that is, according to Hatcher, "self-protecting and systemic." As Thacker (2004: xiii) rightly emphasizes, "You have not sufficiently understood power relations in the control society unless you have understood 'how it works' and 'who it works for."' Ultimately, political and financial self-interest, as well as power dominance, can be tracked upstream to governmental agencies in the name of national state security, or to corporations in the name of free-market ideology.

In performing Drone Pilot (Hatcher 2015b), the theme of black boxes as intermediaries in a highly mass surveilled and controlled society raises the question, what spaces are really private in the private sphere? Not understanding the black box reinforces the deliberate lend of our own language, infrastructures, and systems to machines controlled by the state or the corporation. As Galloway and Thacker (2007: 3) highlight,

The United States has, throughout the last half century or so, dominated the technology driving the world culture and economy, from the Windows operating System to Zoloft to the Boeing 747 aircraft. Thus the idea of "American exceptionalism" is always refracted 
through two crucial lenses of modernity: rapid technological change that, today at least, center around information networks, versus a continued expression of sovereignty alongside the emergence of these global networks.

The political theory of networks that Galloway and Thacker (2007: 3) develop presupposes that power and influence diffused via networks are highly pervasive, in that "processes of globalization" are part of a "a system of control infused into the material fabric of distributed networks." This view goes in line with Michel Foucault's perspective that discourse and language are power, in the sense of being a tool for distributed networks of knowledge. If this was already true in the aftermath of $9 / 11$, it has been definitively exponentiated and made public in the years that followed. After 2006, US secret documents more than twenty-five years old are automatically declassified and hence disclosed to the public. However, today's network access makes them more easily hackable and spreadable. Surveillance, control, and the lack of privacy seem to be now more visible concerns for a portion of the population. That is why contemporary leaked documents become subject of public attention, dissemination, and rapid creative use, whose public scrutiny should have an impact on governance and corporate accountability.

Two major events in the 2010s have had a significant impact in terms of citizen privacy and digital rights. In 2010-11 WikiLeaks released a very large number of diplomatic cables and other documents revealing the pervasive soft and hard power of the US imperialistic strategies with the goal to controlling regional, national, and continental geopolitical areas (Assange 2016). Moreover, surveillance shifted from being a tactic and operational mode used by governmental secret agencies to target suspected criminals, to a generalized system targeting any citizen. Corporate spying programs that aim to increasing knowledge of a competitor's patent and technology development in order to increase profit are entangled with governmental spying programs. These facts became publicly widespread after Edward Snowden's 2013-14 leakage to 
the Guardian and the Washington Post disclosing secret programs undertaken by the NSA and its foreign partners, with semantically charged and sometimes even poetic code names, such as Fairview, Prism, Mystic, Oakstar, Stormbrew, Shiftingshadow, Orangecrush, Mutant Broth, Blarney, Ghostmachine, Gumfish, Turbine, and Captivatedaudience. Some of these programs aim at collecting information by any citizen, in emails, Web chats, social network sites, and at wiretapping, accessing private devices, their built-in cameras, and microphones-with the close collaboration of such tech corporations as Apple, Google, Microsoft, Yahoo, and Facebookwhereas others aim at "infecting" computers and national "critical infrastructure."

By approaching different black boxes, Hatcher creates an analogy at the level of secret agencies and computer systems, from the subjective point of view of the user and the human as sender and receiver. As such, by thematically, structurally, and conceptually addressing that aspect, he denounces it as much as he criticizes it. At the same time, he practices the opposite. As Chun (2006: 71) points out, "Open source and free software, by belonging to no one, makes democratic struggle possible, makes their code functionally analogous to a public place." The inner workings of governmental secret programs and computational interfaces-think of Lori Emerson's (2014) critique of slick interfaces - are increasingly more difficult to understand and more difficult to access. The public eye and interest then become residual aspects of democratic governance. More than counter the power relations and control propagated in networks and protocols with activist language and art, resistance — especially in the way "TRO" is performed — emerges from exposure and exaggeration. The hyperbolical embodiment of speedin the visual and aural performance of textual data streams - reinforces the problems at stake with surveillance, control, and the access to privileged information, but also the abuse of power that often comes with it. 


\section{Performing the Sound Poem}

It is precisely the variables of information overflow, excess, multiple streams of information, transmission speed, denial of access to privileged information, unreadability, and even censorship that the poet embodies and amplifies when performing the piece. However, the reading of the work becomes something else, a complementary iteration of the online poem, a different version or manifestation, a different event. Hatcher's line "speak as clearly as you can" is paradoxical. When performing, his voice utterances become everything except clearly spoken. The poet performs the piece with audio technology, that is, human technology: his own voice, which he used to refer to as "code inflected" (ianhatcher.net). The human vocal aspect is injected by an attempt to mimic broken computer-generated voices.

The sound poem, though, moves away from the high pitch we can associate with such poets as Steve McCaffery, Jaap Blonk, or Christian Bök and the lineage their work derives from, that is, post-WWII authors such as Henri Chopin, François Dufrêne, and Bernard Heidsieck (McCaffery and bpNichol 1978), and especially sound and Dadaist poets like Hugo Ball, Raoul Hausmann, and Kurt Schwitters, such as Schwitters's sound poem "Ursonate" (1922-32). Sound poetry has relied on quick rhythms, high pitch, phonetic sounds taken as nonlinguistic poetry, and powerful utterances. Hatcher's approach to sound poetry is rather different from his predecessors. It is closer to Gertrude Stein's repetitive absurd compositions than to Schwitters's cacophonies. Consider "The Fifteenth of November . . T.S. Eliot" (Stein 1924), where Stein reads, "he said we and we, he said we, he said he and he, he said, we said, he said, yes he said, he said that was the same as that we had heard ... surely as much so, please please us, please please, please please us." Stein relies on repetition, anaphoric structures, and cycles of iterations, which we can encounter in Hatcher's work as well, when stuttering, when code, text, sound, and 
live performance come in full cycles. Hatcher's repetitive copy-paste, cut-up technique and its translation into sharp and short sounds reaches a point where expressions such as "speak as clearly as you can" achieve both polysemic value and what "psychologists call 'semantic saturation," the loss or removal of meaning that "becomes mere sound" (Lerner 2016: 80). In Hatcher's performance of "TRO," the vocal modulations and bass computerized pitch rely on the athletic exercise of speed-reading. In some sense, we can say that Hatcher's performance of his own work is a deformative reading. In other words, performing "TRO” deforms "TRO." Taken from another perspective, the performance of the base theme, which is the text score, is reenacted as embodied versions, an aspect that is fundamental in improvisation, sound poetry, and what Richard Kostelanetz calls "text-sound” (1980).

When Hatcher reads "TRO" as part of Drone Pilot, the same strategy of "Ping" is replicated with the use of the verb "connecting" — an allusion to the fact that the performer and the system are connecting to the host. ${ }^{18}$ Then, Hatcher initiates the piece. From the point of view of the performer, it is a very demanding and extreme reading. Hatcher's athletic reading speed becomes a symbol for a whole era of information overflow, angst, and control. Showing the piece in projection behind his figure, the body of the performer stands in front of the audience. At the same time, Hatcher reads from his mobile phone, an iPhone, which is important inasmuch as it becomes an extension of his own hands, the size of the device being relevant as it is easily manipulated by his thumbs, by now almost becoming extensions of the device. Hatcher controlling the interface and the device articulates living proof of André Leroi-Gourhan's (1993) notion of adaptive evolution of tools and humans.

In fact, the development of human behavior becomes entangled and influenced by the technological tools at their disposal. The curtain and its movement direction, closing and opening 
up, combine a further layer of denotative meaning as they seem to give and withdraw. Code, text, body, sound, interaction, image projection, the disposition on stage, and the live performance are a distinctive case of what Chris Salter would call the "entanglement" of technology and performance arts. Salter builds up on research of complex dynamical systems: “Just as performance is a time-based, nonrepeatable ... practice, so too is the behavior of fluid dynamics or cognitive systems that defy the scientific cornerstone of exact reproducibility due to their continual variance over time" (2010: xxx).

With a very personal idiom, Hatcher embodies the cognition of overflow in networks, as a human-machine symbiosis, a cyborg-like presentiment. If, as Bernard Stiegler (1994) posits, the technical device possesses its own "intratemporality," the extended or prosthetic nature of Hatcher's voice and hands relates to its adaptation to tools. Hatcher's body, more than a cyborg, is a prosthetic device of Hatcher himself, a technical device incorporated in a biologic form. Hatcher, though, plays a trick like a magician. What seems to be a supercomputer brain reading at an impossible speed is, in fact, a vocal technique developed by the author: saccades seem to be inexistent and syllables omitted, so as to appear being read in synchronicity with the visual display. "In the beginning it will be clearer, and then as it goes on I start filling in the space with sounds, syllables," explains the author (Hatcher 2015c: 27:23-27:30). What could be taken as Wallace Stevens's “syllable of a syllable" (1990: 268) is a voice rewriting the text, a voice dismembering language until a point of no intelligible return — consider Jaap Blonk’s “De Minister I" and “De Minister II” ([1985] 1993a; see also Blonk 1993b, 2013).

The audience is tricked to think that a responsive environment is set, that text-to-speech or speech-to-text operations are undergoing. Actually, it is a static text that Hatcher is reading from his mobile phone, the same text in another order, and the utterances that initially seem like 
transparent words gradually transform themselves into syllables and sounds spoken at a very fast pace, resembling words. In a talk at the New Jersey Institute of Technology, Eric Katz asked: "Do you think you capture one percent of the words?" to which Hatcher replied: "I actually capture almost all of them because I am not reading from the screen, but I am reading from the same text, but not in this form [on-screen]" (Hatcher 2015c: 26:51-27:03).

Hatcher's intelligent strategy plays with the fact that, at a certain speed, human scales of faster, or even faster, are dismissed. Speed rates become unintelligible. Human brains have no way to dictate if synchronicity is happening or not, as two highly fast rates of speed are unfolding, yet too fast to be measured or articulated in relation to each other. Still, by chunking parts of the words, the poet vocalizes what seems to be a real-time process of speed-reading. Moreover, a further element in the performance is the relation between the black box and the performer's gesture. When the black box shows on-screen, Hatcher lifts his hand and covers his mouth, hence prompting a moment of silence. The hand seems pulled by a different body, as if a censor, or a censoring system was forcing the subject not to speak up, to be shut down. Then, the reading resolves immediately. At the same time, these breaks act as moments to pause for breath. As the performance progresses the audience fixation on the screen shifts back to the performer's body. Therefore, Hatcher emphasizes human performative qualities, instead of letting hardware and software become the main focus of attention. The rhythm of his voice ascertains that focus. Instead of being outside of the performance, manipulating parameters on his laptop, Hatcher is inside. By his integrating the body, screen, and computational system as presence, a higher level of engagement by the audience surely occurs. 


\section{Conclusion: Multimodal Readings}

This contextual reading of Ian Hatcher's " $U$ (Total Runout)" provides, in itself, a multimodal approach to a work that is published and performed in different manifestations. At the level of theoretical implications, the experimental case study conducted on the modifications of its source code hopes to contribute to a new—or, at least, more informed—way of reading and interpreting digital kinetic poetry and literary works. For, as Nick Montfort and Stephanie Strickland (2013: lines 904-5) point out, "works of electronic literature and digital art need to be studied by operating them." Montfort and Strickland glossed the code of "Sea and Spar Between" (2010); that is, they published criticism about "computational poetics" by writing a log on their creative work in the source code of the work itself. In doing so, they invited critics and artists to modify and remix their code. The method of deforming Hatcher's work through modifications explores this potential avenue, with the aim of fostering a novel comprehension of the processes, and expressive qualities of literary works that move and unfold in time.

To conclude, the performativity of the gestures and the act of reading replicate the structure and theme of " $\square$ (Total Runout)." They point to an embodied denouncement of statal and corporate systems of control, cognition, and violence, systems that, following "the sociotechnological study of the mechanisms of control," mean a "crisis of the institutions, ... the progressive and dispersed installation of a new system of domination" (Deleuze 1992: 7). As Rita Raley (2009: 133) argues, when analyzing electronic network systems, the self-regulatory and self-governance of financial information is that their "function and performance are their meaning." The text behavior and the interactive mechanics — the denial of intelligibility— constitute the very essence of Hatcher's piece in that, as Samuels and McGann (1999) would also argue, they "perform its own meaning." The work's activation, high speed, and prevention of 
access prove the conceptual take. The meaning lies not entirely in the content but in the work's processes to act as powerful reminders of the functions behind networked systems, their hidden control, and the human ability to use them in order to propagate violence.

\section{References}

Assange, Julian. 2016. The WikiLeaks Files: The World According to US Empire. London: Verso.

Bagley, Richard J., and J. Doyne Farmer. 1991. "Spontaneous Emergence of a Metabolism.” In Artificial Life II: Proceedings of the Second International Workshop on the Synthesis and Simulation of Living Systems, edited by Christopher G. Langton, Charles Taylor, J. Doyne Farmer, and Steen Rasmussen, 93-140. Redwood City, CA: Addison-Wesley.

Bervin, Jen. 2004. Nets. Brooklyn, NY: Ugly Duckling Presse.

Blonk, Jaap. (1985) 1993a. “De Minister I,” and “De Minister II.” Liederen uit de Hemel. Amsterdam: Poëzie Perdu 4, n.p. and compact disk. jaapblonk.com/Pages/texts.html

Blonk, Jaap. 1993b. Flux de Bouche. Amsterdam: Staalplaat, STCD046, compact disk.

Blonk, Jaap. 2013. Klinkt. Gent: Het Balanseer.

Borges, Jorge Luis. 2014. Biblioteca Pessoal. Lisbon: Quetzal.

Borsuk, Amaranth, Jesper Juul, and Nick Montfort. 2013. "The Deletionist.” thedeletionist.com.

Chun, Wendy Hui K. 2006. Control and Freedom: Power and Paranoia in the Age of Fiber Optics. Cambridge, MA: MIT Press.

DARPA. n.d. “About DARPA.” darpa.mil/about-us/about-darpa.

Deleuze, Gilles. 1992. "Postscript on the Societies of Control." October no. 59: 3-7.

Deleuze, Gilles, and Félix Guattari. 1994. What Is Philosophy?, translated by Hugh Tomlinson and Graham Burchell. New York: Columbia University Press.

Dworkin, Craig. 2013. No Medium. Cambridge, MA: MIT Press.

Emerson, Lori. 2014. Reading Writing Interfaces: From the Digital to the Bookbound. Minneapolis: University of Minnesota Press.

Ess, Charles. 2009. Digital Media Ethics. Cambridge: Polity Press.

Galloway, Alexander R. 2004. Protocol: How Control Exists after Decentralization. Cambridge, MA: MIT Press.

Galloway, Alexander R., and Eugene Thacker. 2007. The Exploit: A Theory of Networks. Minneapolis: University of Minnesota Press.

Gomringer, Eugen. 1953. Konstellationen. Bern: Spiral Press. 
Hatcher, Ian. 2006. "Occamsparser." ianhatcher.net/texts/occam/.

Hatcher, Ian. 2008. "Opening Sources." openingsources.com/.

Hatcher, Ian. 2009. "Ping." Soundcloud, n.d. soundcloud.com/ihatch/ping

Hatcher, Ian. 2011a. "Working Memory." Springgun 5. springgunpress.com/ihatcher/workingmemory/

Hatcher, Ian. 2011b. "Working Memory Array." Glasschord 1: 10. glasschord.com/ianhatcher/working-memory-array.

Hatcher, Ian. 2014. "Plexus." Get Anomalous 11. anomalouspress.org/11/2.hatcher.plexus.php.

Hatcher, Ian. 2015a. The All-New. Providence, RI: Anomalous Press.

Hatcher, Ian. 2015b. Drone Pilot v0.2. Vimeo, November 16. vimeo.com/145887878.

Hatcher, Ian. 2015c. Ian Hatcher: NJIT Artist Talk. Vimeo, March 10, 2017. vimeo.com/207786761.

Hatcher, Ian. 2015d. “ $\sqcup$ (Total Runout).” Imperial Matters. imperialmatters.com/ian-hatcher.

Hatcher, Ian. 2016. Prosthesis. Portland, OR: Poor Claudia.

Hatcher, Ian. 2017. Drone Pilot. Düsseldorf: cOsmOsmOse, vinyl 7’'.

Holzer, Jenny. Redaction Paintings. New York: Cheim and Read, 2006.

Johnston, David Jhave. 2016. Aesthetic Animism: Digital Poetry's Ontological Implications. Cambridge, MA: MIT Press.

Kostelanetz, Richard, ed. 1980. Text-Sound Texts. New York: William Morrow.

Langton, Christopher G. 1990. "Computation at the Edge of Chaos: Phase Transitions and Emergent Computation.” Physica D: Nonlinear Phenomena 42, no. 1-3: 12-37.

Lerner, Ben. 2016. The Hatred of Poetry. New York: FSG Originals.

Leroi-Gourhan, André. 1993. Gesture and Speech, translated by Anna Bostock Berger. Cambridge, MA: MIT Press.

Lipovetsky, Gilles, and Sébastien Charles. 2004. Les Temps Hypermodernes. Paris: Grasset.

Lipovetsky, Gilles, and Jean Serroy. 2011. L'Écran Global: Du Cinéma au Smartphone. Paris: Éditions du Seuil.

McCaffery, Steve, and bpNichol, eds. 1978. Sound Poetry: A Catalogue. Toronto: Underwhich Editions.

Melley, Timothy. 2012. The Covert Sphere: Secrecy, Fiction, and the National Security State. Ithaca, NY: Cornell University Press.

Montfort, Nick, and Stephanie Strickland. 2010. "Sea and Spar Between." In Vol. 3 of Electronic Literature Collection, edited by Stephanie Boluk, Leonardo Flores, Jacob Garbe, and Anastasia Salter. Cambridge: ELO. collection.eliterature.org/3/work.html?work=sea-andspar-between. 
Montfort, Nick, and Stephanie Strickland. 2013. "cut to fit the toolspun course: Discussing Creative Code in Comments." Digital Humanities Quarterly 7: 1. digitalhumanities.org/dhq/vol/7/1/000149/000149.html.

Muuss, Michael. n.d. “The Story of the PING Program.” ftp.arl.army.mil/ mike/ping.html.

Niiler, Eric. 2012. "New Navy Fighter Drone Promises Pilotless Future.” Seeker, August 2. seeker.com/new-navy-fighter-drone-promises-pilotless-future-1765906891.html.

Raley, Rita. 2009. Tactical Media. Minneapolis: University of Minnesota Press.

Rankine, Claudia. 2014. Citizen: An American Lyric. Minneapolis, MN: Graywolf Press.

Salter, Chris. 2010. Entangled: Technology and the Transformation of Performance. Cambridge, MA: MIT Press.

Samuels, Lisa, and Jerome McGann. 1999. "Deformance and Interpretation.” New Literary History 30, no. 1: 25-56. doi:10.1353/nlh.1999.0010.

Sanger, David E. 2012. “Obama Order Sped Up Wave of Cyberattacks against Iran.” New York Times, June 1. nytimes.com/2012/06/01/world/middleeast/obama-ordered-wave-ofcyberattacks-against-iran.html.

Schwitters, Kurt. 1922-32. "Ursonate.” PennSound. writing.upenn.edu/pennsound/x/Schwitters.php

Seiça, Álvaro. 2015a. "Against the Grain: A Conversation with Stephanie Strickland." "setInterval() Conversation Series 7," November 24. In "setInterval(): Time-Based Readings of Kinetic Poetry.” PhD diss., University of Bergen, 2018: 394-429. hdl.handle.net/1956/17267.

Seiça, Álvaro. 2015b. "Rendering Time: A Conversation with Ian Hatcher." "setInterval() Conversation Series 9." Vimeo, March 10, 2017. vimeo.com/207815551.

Seiça, Álvaro. 2020. “Lit Mods.” Electronic Book Review, September 6. electronicbookreview.com/essay/lit-mods/

Stein, Gertrude. 1934-35. "The Fifteenth of November . . T.S. Eliot." [Stein's own reading title is "A Description of the Fifteenth of November: A Portrait of T.S. Eliot."] UbuWeb Sound. ubu.com/sound/stein.html.

Stevens, Wallace. 1990. "The Search for Sound Free from Motion." In The Collected Poems of Wallace Stevens, 268. New York: Vintage Books.

Stiegler, Bernard. 1994. La Technique et le Temps, 1: La Faute d'Epiméthée. Paris: Galilée.

Thacker, Eugene. 2004. "Foreword: Protocol Is as Protocol Does.” In Galloway 2004: xi-xxii.

UK Ministry of Defence. 2001. "The Defence Manual of Security," 1-3, no. 2.

Virilio, Paul. 1999. Politics of the Very Worst. New York: Semiotext(e).

WikiLeaks. 2009. "UK MoD Manual of Security Volumes 1, 2 and 3 Issue 2, JSP-440, RESTRICTED, 2389 pages, 2001." WikiLeaks, October 4.

wikileaks.org/wiki/UK_MoD_Manual_of_Security_Volumes_1,_2_and_3_Issue_2,_JSP440,_RESTRICTED,_2389_pages,_2001. 


\section{Endnotes}

1 "TRO" is the same initialism used by Hatcher (2015d) in the source code.

2 "Occamsparser" shares affiliations with various works. Consider, for example, Nets (2004) by Jen Bervin or "The Deletionist" (2013) by Amaranth Borsuk, Jesper Juul, and Nick Montfort. See also Craig Dworkin's No Medium (2013).

${ }^{3}$ Ian Hatcher, email message to author, February 6, 2017.

${ }^{4}$ A ping is an Internet Control Message Protocol (ICMP). The reader can run the command line "ping domain" (where "ping" is followed by a specific domain) in the computer's terminal. For example, if we want to ping the domain of the sound poem "Ping," we can type "ping ianhatcher.net." The result would be "PING ianhatcher.net (64.111.126.223) : 56 data bytes" and then a sequence of message pings informing about the amount of data transferred, the IP address, and the round-trip time in milliseconds, which is always changing: "64 bytes from 64.111.126.223: icmp_seq=0 ttl=47 time=144.172 ms." Aborting the program provides average statistics: "--- [domain] ping statistics --- [x] packets transmitted, $[\mathrm{x}]$ packets received, [x]\% packet loss round-trip $\mathrm{min} / \mathrm{avg} / \mathrm{max} / \mathrm{stddev}=[\mathrm{x} / \mathrm{x} / \mathrm{x} / \mathrm{x}] \mathrm{ms} . "$

${ }^{5}$ Muuss named it after an analogy with the sonar's echolocation, as "ping" represents the sound sonars emit (Muuss n.d.).

${ }^{6}$ DARPA (Defense Advanced Research Projects Agency), formerly Advanced Research Projects Agency (ARPA), is part of the US Department of Defense. The relation between national security, the military industry and technological development is clear in the agency's mission statement: "The genesis of that mission and of DARPA itself dates to the launch of Sputnik in 1957, and a commitment by the United States that, from that time forward, it would be the initiator and not the victim of strategic technological surprises. Working with innovators inside and outside of government, DARPA has repeatedly delivered on that mission, transforming revolutionary concepts and even seeming impossibilities into practical capabilities. The ultimate results have included not only game-changing military capabilities such as precision weapons and stealth technology, but also such icons of modern civilian society such as the Internet, automated voice recognition and language translation, and Global Positioning System receivers small enough to embed in myriad consumer devices" (DARPA n.d., emphasis added).

${ }^{7}$ Consider, for instance, the so-called Stuxnet malware implant, code-named Operation Olympic Games. See Sanger 2012.

${ }^{8}$ For a visualization of drone attacks in Pakistan, visit drones.pitchinteractive.com/ or access an API (Application Programming Interface) for US drone strikes at dronestre.am/. The increase in recruitment of people with high coding skills, such as former army personnel or academic students, is reinforced by the creation of curricula at universities under the rhetoric of "national security." See, for instance, the Common Mission Project's "Hacking for Defense®" course, described at commonmission.us/.

${ }^{9}$ Note that Hatcher is a professional daytime programmer at an IT company.

${ }^{10}$ The full source text, now called variable "rem," was published as "Working Memory Array" (2011b).

${ }^{11}$ For examples of all members of the Proxima Nova type family, see marksimonson.com/fonts/view/proxima-nova.

${ }^{12}$ The library jquery.transit.js for jQuery creates CSS3 "transformations and transitions." Filipino Web developer Rico Sta. Cruz wrote it and released it under an MIT license via GitHub, at github.com/rstacruz/jquery.transit.

${ }^{13}$ The modified version can be accessed at alvaroseica.net/setInterval/tro/TROmod.html.

${ }^{14}$ The video can be accessed at vimeo.com/206581420.

${ }^{15}$ The use of documents in artworks has a long tradition in theater, and the same is true in literature and the visual arts. Consider Jenny Holzer's post-2003 work with declassified documents, under the US 1966 Freedom of Information Act. The Redaction Paintings, Archive (2006) and Top Secret (2012) series of silk-screened and oil paintings are composed from confidential memos, emails, or documents concerning Abu Ghraib. They are presented 
as redacted visual documents, showing marks by government censors or Holzer's color blocks superimposed over text portions.

${ }^{16}$ Hatcher, email.

${ }^{17}$ Oxford English Dictionary, s.v. "black box," en.oxforddictionaries.com/definition/black_box.

${ }^{18}$ See, e.g., Hatcher 2015b for his performance at Judson Memorial Church, in New York City. 